\title{
Self-Rated Health Status and Risk of Incident Stroke in 0.5 Million Chinese Adults: The China Kadoorie Biobank Study
}

\author{
Wenhong Dong, ${ }^{\mathrm{a}}$ Xiong-Fei Pan, ${ }^{\mathrm{a}}$ Canqing Yu, ${ }^{\mathrm{b}}$ Jun Lv, ${ }^{\mathrm{b}}$ Yu Guo, ${ }^{\mathrm{c}}$ Zheng Bian, ${ }^{\mathrm{c}}$ Ling Yang, ${ }^{\mathrm{d}}$ \\ Yiping Chen, ${ }^{\mathrm{d}}$ Tangchun $\mathrm{Wu},{ }^{\mathrm{a}}$ Zhengming Chen, ${ }^{\mathrm{d}}$ An Pan, ${ }^{\mathrm{a}}$ Liming Li, ${ }^{\mathrm{b}, \mathrm{c}}$ on behalf of the China \\ Kadoorie Biobank Collaborative Group \\ ${ }^{a}$ Department of Epidemiology and Biostatistics, and Ministry of Education Key Laboratory of Environment and Health, and State Key Laboratory \\ of Environmental Health (Incubating), Tongji Medical College, Huazhong University of Science and Technology, Wuhan, China \\ ${ }^{b}$ Department of Epidemiology and Biostatistics, School of Public Health, Peking University Health Science Center, Beijing, China \\ 'Chinese Academy of Medical Sciences, Beijing, China \\ ${ }^{d}$ Clinical Trial Service Unit \& Epidemiological Studies Unit (CTSU), Nuffield Department of Population Health, University of Oxford, Oxford, UK
}

Background and purpose Self-rated health (SRH) is a consistent and strong predictor of all-cause and cardiovascular mortality in various populations. However, the associations between SRH measures and risk of first-ever or recurrent stroke were rarely explored. We thus aim to prospectively investigate the associations between SRH measures and risk of total and subtypes of stroke in Chinese population.

Methods A total of 494,113 participants from the China Kadoorie Biobank without prior heart diseases or cancer (486,541 without stroke and 7,572 with stroke) were followed from baseline (2004 to 2008) until December 31, 2013. General and age-comparative SRH were obtained from baseline questionnaires. First-ever stroke or recurrent events were ascertained through linkage to disease registry system and health insurance data.

Results We identified 27,662 first-ever stroke and 2,909 recurrent events during an average of 7.0 years of follow-up. Compared with excellent general SRH, the hazard ratios (HRs) and 95\% confidence intervals (Cls) for first-ever stroke associated with good, fair, and poor general SRH were 1.04 (1.00 to 1.08$), 1.19$ (1.15 to 1.23$)$, and 1.49 (1.42 to 1.56$)$ in the multivariate model, respectively. Compared with better age-comparative $\mathrm{SRH}$, the HRs (95\% Cls) of same and worse age-comparative SRH were 1.13 (1.10 to 1.17) and 1.51 (1.45 to 1.58), respectively. The relations of $\mathrm{SRH}$ measures with ischemic stroke, hemorrhagic stroke, and recurrent stroke were similar to that with total first-ever stroke. However, the magnitude of associations was much stronger for fatal stroke than for non-fatal stroke.

Conclusions This large-scale prospective cohort suggests that self-perceived health status is associated with incident stroke, regardless of stroke subtype.
Correspondence: An Pan Department of Epidemiology and Biostatistics, Tongji Medical College, Huazhong University of Science and Technology, 13 Hangkong Rd, Wuhan 430030, China

Tel: +86-27-83627309

Fax: +86-27-83627309

E-mail: panan@hust.edu.cn

Co-correspondence: Liming Li Department of Epidemiology and Biostatistics, School of Public Health, Peking University Health Science Center, 38 Xueyuan Rd, Beijing 100191, China

Tel: +86-10-82801528

Fax: +86-10-82801528

E-mail: Imleeph@vip.163.com

Received: July 29, 2017

Revised: November 25, 2017

Accepted: March 18, 2018

Keywords Health status; Stroke; Prospective studies 


\section{Introduction}

Despite great improvements in medical care and decreasing age-standardized mortality, stroke has constantly been a leading cause of mortality and disability-adjusted life-years in China. ${ }^{1,2}$ According to a nation-wide survey in 2013, approximately 2.4 million newly-onset stroke and 1.1 million stroke deaths occurred annually, making China a country with greatest burden of stroke worldwide. ${ }^{3}$ Additionally, the rising prevalence of risk factors for stroke such as obesity, diabetes, and population aging were projected to further increase the incidence of stroke, as was already found in rural China. ${ }^{4,5}$ Thus, it is of great importance to scale-up the primary prevention actions; in addition, the identification of more potential risk factors and predictors, especially easily obtained factors, may be beneficial in the perspective of public health.

Self-rated health (SRH) status, often used in the form of general SRH and/or age-comparative SRH, is a relatively subjective and multifaceted measure of personal health. It has been found to be an independent predictor of all-cause mortality ${ }_{1}^{6-9}$ cardiovascular morbidity and mortality ${ }^{8-13}$ in various populations. However, the predictive value of SRH on incident stroke was less investigated. To our best knowledge, only four studies had evaluated the association with inconsistent findings. ${ }^{13-16}$ Additionally, none of the studies explored whether the associations were different across stroke subtypes, or whether age-comparative SRH was associated with incident stroke. In addition, no study has evaluated the association between SRH and stroke morbidity in Chinese population.

We therefore used data from an ongoing prospective cohort study, the China Kadoorie Biobank (CKB) study, to prospectively investigate the relationships of both general SRH and agecomparative SRH with risk of stroke.

\section{Methods}

\section{Study population}

Detailed information of the CKB study design, sampling strategy, survey methods, and long-term follow-up have been reported elsewhere. ${ }^{17}$ Briefly, a total of 512,891 participants aged 30 to 79 years old from 10 regions of China were enrolled between 2004 and 2008. Baseline information including demographic characteristics, personal medical history, mental health, and lifestyles was obtained by trained staff from local Centers for Disease Control and Prevention (CDC) and survey teams through face-to-face interviews. Height, weight, and blood pressures were measured for each participant.

For this study, we excluded participants with a prior history of cancer $(n=2,577)$, coronary heart disease $(n=15,472)$, rheumatic heart disease $(n=938)$, or stroke $(n=8,884)$, as well as two individuals with missing values of body mass index (BMI). Finally, a total of 486,541 participants $(199,113$ men and 287,428 women) were included in the analysis of SRH measures and first-ever stroke, while 7,572 participants with prior history of stroke remained for the analysis of SRH measures and recurrent stroke after excluding those with cancer $(n=64)$, coronary heart disease $(n=1,227)$, and rheumatic heart disease $(n=46)$ at baseline ( 25 of them had more than one disease).

The study was approved by the Ethical Review Committee of the Chinese CDC (Beijing, China) and the Oxford Tropical Research Ethics Committee, University of Oxford (Oxford, United Kingdom). Written informed consent forms were obtained from all participants.

Assessment of general and age-comparative SRH SRH status was inquired by two questions at baseline: (1) how is your current general health status: excellent, good, fair, or poor? and (2) how is your current health status compared with someone of your own age: better, about the same, worse, or don't know? The first question was considered as general SRH and the second as age-comparative SRH. Participants answering "don't know" for the second question ( $n=14,990,3.1 \%)$ were further excluded for analysis of the association between age-comparative SRH and stroke risk.

\section{Ascertainment of stroke mortality and morbidity} Stroke mortality and morbidity of each participant was obtained by regular linkage to regional disease and death registers and with the national health insurance database. ${ }^{17}$ For those who were not included in the system, dedicated staff members annually ascertained their status including disease development, hospital admission, death, and migration. Presently, $98 \%$ of the study population was covered by the health insurance system. Follow-up information was complete for $99.4 \%$ of the participants.

Stroke was defined as a focal neurological deficit of sudden or rapid onset lasting $\geq 24$ hours or until death, confirmed by computed tomography or magnetic resonance imaging. A fatal stroke event was one resulting in death within 28 days; a nonfatal event denoted survival at least 28 days after stroke onset. ${ }^{18}$ All new cases were coded as 160 (subarachnoid stroke), I61 (hemorrhagic stroke), I63 (ischemic stroke), I64 (other or unknown stroke type) according to the International Classification of Diseases, 10th reversion by trained staff. 


\section{Covariates}

Demographic and socioeconomic characteristics such as age, sex, study area (10 regions), marital status (married, widowed, separated/divorced, and never married), education (no formal education, 1 to 6,7 to 13 , and $\geq 14$ years of education), annual household income $(<10,000,10,000$ to $19,999,20,000$ to 34,999 , and $\geq 35,000$ Yuan), occupation (farmers, factory workers, professionals and managers, retirees, unemployed and others), house/apartment owning (yes, no), and healthcare coverage (yes, no) were obtained in baseline interview. Lifestyle factors were also inquired, including smoking status (never, former, occasionally, and current smoker), alcohol drinking (never, former, occasionally, and weekly drinker), physical activity (calculated as metabolic equivalent tasks hours for daily work or leisure activities) and sleep problems (yes, no). Women were additionally asked about their menopausal status (pre-, peri-, and post-menopause). Family history of stroke (yes, no) and personal medical history (hypertension, diabetes, and 11 other medical conditions including tuberculosis, asthma, cirrhosis, chronic hepatitis, peptic ulcer, gall/bladder stone, kidney disease, fracture, rheumatoid arthritis, psychiatric disorder, and head injury) were also obtained. Participants with a fasting plasma glucose $\geq 7.0 \mathrm{mmol} / \mathrm{L}$, or random blood glucose $\geq 11.1$ $\mathrm{mmol} / \mathrm{L}$, or self-reported diagnosis of diabetes mellitus were defined as having prevalent diabetes. ${ }^{19}$ Participants reporting diagnosis of hypertension, or measured systolic blood pressure $\geq 140 \mathrm{~mm} \mathrm{Hg}$ and/or diastolic blood pressure $\geq 90 \mathrm{~mm} \mathrm{Hg}$ were considered as having prevalent hypertension. ${ }^{20}$ The Chinese version of computerized Composite International Diagnostic Inventory-short form (CIDI-SF) was used to assess past year major depressive episodes. ${ }^{21} \mathrm{BMI}$ was calculated as measured weight in kilograms divided by the square of height in meters.

\section{Statistical analyses}

Baseline characteristics according to SRH categories were compared using analysis of variance and chi-square tests for continuous and categorical variables, respectively. Person-years were calculated by entry into the study until the onset of stroke, death, loss to follow-up, or December 31, 2013, whichever came first. Multivariate Cox proportional hazards regression were used to estimate hazard ratios (HRs) and 95\% confidence intervals ( $\mathrm{Cls}$ ) for associations between SRH measures and incident stroke after proportional assumption was tested and no violation was identified. Two models were used in analysis: (1) model 1 adjusted for age (continuous), marital status, education, annual household income, occupation, healthcare coverage, housing condition, menopausal status, sleep problems, cigarette smoking, alcohol drinking, physical activity (continuous), BMI (continuous), and family history of stroke; (2) model 2 adjusted for model 1 plus baseline presence of major depressive episodes, diabetes, hypertension, and other prevalent diseases (yes, no). The definitions of all categorical variables were illustrated in the "Covariates" section.

Stratified analysis were performed according to age groups (30 to 64 and $\geq 65$ years old), sex, administrative regions, education, annual household income, cigarette smoking, alcohol drinking, physical activity groups (three groups-low, moderate, and high-were generated according to the tertiles of physical activity), BMI groups ( $<18.5,18.5$ to $23.9,24.0$ to 27.9 , and $\geq 28.0 \mathrm{~kg} / \mathrm{m}^{2}$ ), hypertension, and diabetes. Tests for interaction were conducted by adding interaction terms in the multivariate model. Finally, sensitivity analyses were performed by excluding major depressive episodes, baseline comorbidities (diabetes, hypertension, and other comorbidities), or those who died or developed stroke in the first 2 years of follow-up. All Cox models were conducted with stratification according to age at baseline (in 5-year intervals), sex, and study areas when appropriate.

For all analyses, general and age-comparative SRH were analyzed separately as exposures; we also incorporated the two measures in one model to explore whether they were independent of each other. In addition, first-ever hemorrhagic, ischemic, fatal, non-fatal stroke, and recurrent stroke were also analyzed as outcomes separately. All data analyses were conducted using SAS version 9.3 (SAS Institute Inc., Cary, NC, USA), two-sided $P$-values $<0.05$ were considered as statistical significance.

\section{Results}

Baseline characteristics stratified by general SRH categories are shown in Table 1. Among the 486,541 participants, 88,340 (18.2\%) reported excellent general SRH, 141,022 good (29.0\%), 212,158 fair (43.6\%), and 45,021 (9.2\%) reported poor SRH. Individuals reporting poor general SRH were more likely to be older, female, unmarried, poor, physical inactive, postmenopausal (women), from rural China and had a higher prevalence of sleep problems, diabetes, hypertension, major depressive episodes, or other medical conditions; and they were less likely to have higher education level and healthcare coverage, or own houses, to be employed, current smokers or weekly drinkers (all $P<0.001)$.

Baseline characteristics according to age-comparative SRH are presented in Supplemental Table 1. In 486,541 participants, 90,738 (18.7\%) reported better, 309,022 (63.5\%) reported same, and 71,791 (14.8\%) reported worse age-comparative 
Table 1. Baseline characteristics according to general self-rated health status

\begin{tabular}{|c|c|c|c|c|c|}
\hline \multirow[b]{2}{*}{ Characteristic } & \multirow{2}{*}{$\begin{array}{c}\text { Total } \\
(\mathrm{n}=486,541)\end{array}$} & \multicolumn{4}{|c|}{ General self-rated health } \\
\hline & & $\begin{array}{l}\text { Excellent } \\
(n=88,340)\end{array}$ & $\begin{array}{c}\text { Good } \\
(n=141,022)\end{array}$ & $\begin{array}{c}\text { Fair } \\
(n=212,158)\end{array}$ & $\begin{array}{c}\text { Poor } \\
(n=45,021)\end{array}$ \\
\hline \multicolumn{6}{|l|}{ Sociodemographic factor } \\
\hline Age, mean $\pm S D(y r)$ & $51.0 \pm 10.5$ & $49.4 \pm 10.4$ & $50.4 \pm 10.3$ & $51.8 \pm 10.6$ & $52.7 \pm 10.7$ \\
\hline Female sex (\%) & 59.1 & 53.5 & 57.5 & 61.0 & 65.9 \\
\hline Married (\%) & 90.9 & 92.2 & 92.2 & 90.1 & 87.9 \\
\hline No formal education (\%) & 18.7 & 15.1 & 20.4 & 17.1 & 24.8 \\
\hline Annual household income $\geq 35,000$ Yuan (\%) & 18.1 & 24.2 & 20.4 & 15.8 & 10.0 \\
\hline Unemployed or not stated (\%) & 14.3 & 11.9 & 12.2 & 15.7 & 19.7 \\
\hline Healthcare coverage (\%) & 82.1 & 86.2 & 83.9 & 80.3 & 76.4 \\
\hline House/apartment owning (\%) & 44.6 & 46.2 & 48.6 & 42.8 & 37.0 \\
\hline Rural area (\%) & 56.9 & 44.0 & 63.2 & 56.5 & 64.2 \\
\hline \multicolumn{6}{|l|}{ Lifestyle factor } \\
\hline Current regular smoker (\%) & 26.8 & 30.5 & 28.3 & 24.9 & 23.5 \\
\hline Weekly alcohol drinker (\%) & 15.1 & 19.8 & 16.8 & 13.2 & 10.0 \\
\hline Physical activity, mean \pm SD (MET-hr/day) & $21.6 \pm 13.9$ & $22.7 \pm 13.8$ & $23.4 \pm 14.4$ & $20.4 \pm 13.5$ & $19.1 \pm 13.5$ \\
\hline Sleep problems (\%) & 16.4 & 9.4 & 13.0 & 18.0 & 33.1 \\
\hline \multicolumn{6}{|l|}{ Personal/family medical history } \\
\hline $\mathrm{BMI}$, mean $\pm \mathrm{SD}\left(\mathrm{kg} / \mathrm{m}^{2}\right)$ & $23.6 \pm 3.4$ & $23.8 \pm 3.2$ & $23.7 \pm 3.3$ & $23.5 \pm 3.4$ & $23.3 \pm 3.7$ \\
\hline Postmenopausal (women only) (\%) & 50.7 & 41.6 & 47.2 & 54.0 & 60.8 \\
\hline Family history of stroke (\%) & 17.5 & 17.4 & 17.2 & 17.3 & 19.9 \\
\hline Prevalent diabetes (\%) & 5.4 & 3.6 & 3.8 & 6.1 & 10.5 \\
\hline Prevalent hypertension (\%) & 32.6 & 28.3 & 31.7 & 34.0 & 37.3 \\
\hline Prevalent major depressive episodes (\%) & 0.6 & 0.2 & 0.3 & 0.6 & 2.1 \\
\hline Other prevalent medical conditions (\%) & 21.9 & 17.5 & 18.2 & 23.0 & 36.9 \\
\hline
\end{tabular}

Two-sided $P$-values were derived from ANOVA for continuous variables and from the chi-square test for categorical variables, all $P$-values comparing the difference between general self-rated health status groups $<0.001$.

SD, standard deviation; MET, metabolic equivalent; BMI, body mass index.

SRH. Comparisons of characteristics between better and worse age-comparative SRH were consistent with those between excellent and poor general SRH.

During $7.0 \pm 1.5$ years of follow-up, a total of 27,662 first-ever stroke cases (5.69\%) were identified (5,287 hemorrhagic stroke [intracerebral or subarachnoid], 21,449 ischemic stroke, and 926 other or unspecified stroke), among which 3,519 events were fatal and 24,143 cases were non-fatal. The HR comparing excellent with poor general SRH after adjustment for sociodemographic factors, lifestyles, and family history of stroke (Table 2) was $1.65(95 \% \mathrm{Cl}, 1.58$ to 1.73$)$, and it was slightly weakened to $1.49(95 \% \mathrm{Cl}, 1.42$ to 1.56$)$ after further controlling for various comorbidities. Similar magnitudes of association were found with hemorrhagic and ischemic stroke, while the association was stronger for fatal stroke (HR, 1.92; $95 \% \mathrm{Cl}, 1.69$ to 2.19$)$ than non-fatal stroke $(\mathrm{HR}, 1.43 ; 95 \% \mathrm{Cl}$, 1.36 to 1.51 ) (Table 2). The survival curves by general SRH was depicted in Figure 1 and Supplementary Figure 1.

Significant interactions were found between general SRH with age, administrative region, education, and BMI status in terms of the risk of total stroke (all $P_{\text {interaction }}<0.05$ ); the association was stronger in younger participants, those from rural regions, those with higher education levels, and those with lower BMI (Figure 2 and Supplementary Table 2).

Relative to those who reported better age-comparative SRH status, participants reporting worse age-comparative SRH had a $51 \%$ increased risk of developing stroke $(\mathrm{HR}, 1.51 ; 95 \% \mathrm{Cl}, 1.45$ to 1.58) (Table 2). Similarly, the association was slightly stronger for fatal stroke $(\mathrm{HR}, 1.81 ; 95 \% \mathrm{Cl}, 1.62$ to 2.03$)$ than with nonfatal stroke (HR, 1.47; $95 \% \mathrm{Cl}, 1.40$ to 1.53 ) (Table 2). The survival curves according to age-comparative SRH were shown in Figure 1 and Supplementary Figure 1. In stratified analyses, effect modification by education, income, cigarette smoking, and alcohol drinking was observed; the association was stronger for 
Table 2. Association of SRH measures with risk of categories of first-ever stroke and recurrent stroke*

\begin{tabular}{|c|c|c|c|c|c|}
\hline Outcomes & Exposures & Cases/person-years & Number & $\begin{array}{c}\text { Model } 1^{+} \\
\text {HR }(95 \% \text { Cl) }\end{array}$ & $\begin{array}{c}\text { Model } 2^{\dagger} \\
\text { HR }(95 \% \text { Cl) }\end{array}$ \\
\hline \multirow[t]{9}{*}{ First-ever stroke } & General SRH & & & & \\
\hline & Excellent & $4,204 / 624,889$ & 88,340 & 1.00 & 1.00 \\
\hline & Good & $6,487 / 1,011,388$ & 141,022 & $1.06(1.02-1.10)$ & $1.04(1.00-1.08)$ \\
\hline & Fair & $13,332 / 1,476,873$ & 212,158 & $1.25(1.21-1.30)$ & $1.19(1.15-1.23)$ \\
\hline & Poor & $3,639 / 311,654$ & 45,021 & $1.65(1.58-1.73)$ & $1.49(1.42-1.56)$ \\
\hline & Age-comparative S & & & & \\
\hline & Better & $4,881 / 649,274$ & 90,738 & 1.00 & 1.00 \\
\hline & Same & $16,635 / 2,173,173$ & 309,022 & $1.18(1.14-1.22)$ & $1.13(1.10-1.17)$ \\
\hline & Worse & $5,121 / 502,526$ & 71,791 & $1.66(1.60-1.73)$ & $1.51(1.45-1.58)$ \\
\hline \multirow[t]{9}{*}{ Hemorrhagic stroke } & General SRH & & & & \\
\hline & Excellent & $647 / 608,810$ & 84,783 & 1.00 & 1.00 \\
\hline & Good & $1,329 / 988,044$ & 135,864 & $1.12(1.02-1.23)$ & 1.09 (0.99-1.20) \\
\hline & Fair & $2,471 / 1,429,038$ & 201,297 & $1.24(1.13-1.35)$ & $1.18(1.08-1.29)$ \\
\hline & Poor & $840 / 299,326$ & 42,222 & 1.79 (1.60-1.99) & $1.62(1.46-1.81)$ \\
\hline & Age-comparative S & & & & \\
\hline & Better & $762 / 630,069$ & 86,619 & 1.00 & 1.00 \\
\hline & Same & $3,238 / 2,114,115$ & 295,625 & $1.17(1.08-1.27)$ & $1.14(1.05-1.23)$ \\
\hline & Worse & 1,138/484,995 & 67,808 & $1.70(1.54-1.87)$ & $1.57(1.42-1.73)$ \\
\hline \multirow[t]{9}{*}{ Ischemic stroke } & General SRH & & & & \\
\hline & Excellent & $3,424 / 621,693$ & 87,560 & 1.00 & 1.00 \\
\hline & Good & $4,948 / 1,005,099$ & 139,483 & $1.05(1.01-1.10)$ & 1.03 (0.99-1.08) \\
\hline & Fair & $10,436 / 1,465,266$ & 209,262 & $1.26(1.21-1.31)$ & $1.20(1.15-1.25)$ \\
\hline & Poor & $2,641 / 307,795$ & 44,023 & $1.61(1.53-1.70)$ & $1.45(1.38-1.53)$ \\
\hline & Age-comparative S & & & & \\
\hline & Better & $3,968 / 645,403$ & 89,825 & 1.00 & 1.00 \\
\hline & Same & $12,883 / 2,158,145$ & 305,270 & $1.18(1.14-1.23)$ & $1.14(1.10-1.18)$ \\
\hline & Worse & $3,759 / 497,264$ & 70,429 & $1.65(1.57-1.73)$ & 1.49 (1.42-1.57) \\
\hline \multirow[t]{9}{*}{ Fatal stroke } & General SRH & & & & \\
\hline & Excellent & $406 / 607,949$ & 84,542 & 1.00 & 1.00 \\
\hline & Good & 791/986,088 & 135,326 & $1.09(0.96-1.23)$ & $1.06(0.94-1.20)$ \\
\hline & Fair & $1,615 / 1,426,221$ & 200,441 & $1.34(1.19-1.49)$ & $1.27(1.13-1.42)$ \\
\hline & Poor & $707 / 298,960$ & 42,089 & $2.14(1.88-2.44)$ & $1.92(1.69-2.19)$ \\
\hline & Age-comparative S & & & & \\
\hline & Better & $518 / 629,292$ & 86,375 & 1.00 & 1.00 \\
\hline & Same & 1,971/2,109,701 & 294,358 & $1.21(1.09-1.34)$ & $1.17(1.06-1.29)$ \\
\hline & Worse & $923 / 484,323$ & 67,593 & $1.99(1.78-2.22)$ & $1.81(1.62-2.03)$ \\
\hline \multirow[t]{9}{*}{ Non-fatal stroke } & General SRH & & & & \\
\hline & Excellent & $3,798 / 623,080$ & 87,934 & 1.00 & 1.00 \\
\hline & Good & $5,696 / 1,007,867$ & 140,231 & $1.06(1.01-1.10)$ & $1.04(1.00-1.08)$ \\
\hline & Fair & $11,717 / 1,469,778$ & 210,543 & $1.25(1.20-1.30)$ & $1.18(1.14-1.23)$ \\
\hline & Poor & $2,932 / 308,775$ & 44,314 & $1.58(1.51-1.67)$ & $1.43(1.36-1.51)$ \\
\hline & Age-comparative S & & & & \\
\hline & Better & $4,363 / 646,869$ & 90,220 & 1.00 & 1.00 \\
\hline & Same & $14,664 / 2,164,519$ & 307,051 & $1.17(1.13-1.22)$ & $1.13(1.09-1.17)$ \\
\hline & Worse & $4,198 / 498,788$ & 70,868 & $1.62(1.55-1.69)$ & $1.47(1.40-1.53)$ \\
\hline
\end{tabular}


Table 2. Continued

\begin{tabular}{|c|c|c|c|c|c|}
\hline Outcomes & Exposures & Cases/person-years & Number & $\begin{array}{c}\text { Model } 1^{+} \\
\text {HR }(95 \% \text { Cl) }\end{array}$ & $\begin{array}{c}\text { Model } 2^{\dagger} \\
\text { HR (95\% Cl) }\end{array}$ \\
\hline \multirow[t]{9}{*}{ Recurrent stroke } & General SRH & & & & \\
\hline & Excellent & $210 / 3,285$ & 585 & 1.00 & 1.00 \\
\hline & Good & $319 / 4,960$ & 881 & $1.27(1.06-1.52)$ & $1.26(1.06-1.51)$ \\
\hline & Fair & $1,272 / 18,806$ & 3,416 & $1.27(1.09-1.48)$ & $1.26(1.08-1.46)$ \\
\hline & Poor & $1,108 / 13,805$ & 2,690 & $1.50(1.28-1.75)$ & $1.46(1.25-1.70)$ \\
\hline & Age-comparative & & & & \\
\hline & Better & $226 / 3,585$ & 622 & 1.00 & 1.00 \\
\hline & Same & $1,128 / 17,585$ & 3,173 & $1.16(1.00-1.34)$ & $1.14(1.00-1.32)$ \\
\hline & Worse & $1,483 / 18,510$ & 3,554 & $1.48(1.28-1.71)$ & $1.43(1.23-1.65)$ \\
\hline
\end{tabular}

$\mathrm{SRH}$, self-rated health; $\mathrm{HR}$, hazard ratio; $\mathrm{Cl}$, confidence interval.

*A total of 486,541 participants were included in the analysis of SRH measures and first-ever stroke, and 7,572 participants with prior history of stroke were included for the analysis of SRH measures and recurrent stroke; ${ }^{\dagger}$ Model 1: Stratified by age ( 5 years intervals), sex, region (10 areas) and adjusted for age (continuous), marital status, education, annual household income, occupation, healthcare coverage, housing condition, menopausal status, sleep problems, cigarette smoking, alcohol drinking, physical activity (continuous), body mass index (continuous), and family history of stroke; ${ }^{*}$ Model 2 : Model 1 plus presence of major depressive episodes, diabetes, hypertension, and other prevalent diseases (yes, no). The categories and definitions of all categorical variables were illustrated in the 'Covariates' section of the Methods.

participants with higher education and income, and who were former smoker and drinker (Supplemental Table 3).

In sensitivity analyses, associations of both general and agecomparative SRH with risk of first-ever stroke and stroke subtype merely changed (Supplemental Table 4). When general SRH and age-comparative SRH were incorporated into one model, their effect sizes were attenuated but both remained significant (Supplemental Table 5).

Among 7,572 participants with prior stroke, 2,909 developed another stroke during follow-up. The HR comparing poor with excellent general $\mathrm{SRH}$ was $1.46(95 \% \mathrm{Cl}, 1.25$ to 1.70$)$ and 1.43 (95\% Cl, 1.23 to 1.65 ) comparing worse with better age-comparative general SRH (Table 2). The survival curves free of recurrent stroke by SRH measures were presented in Figure 1.

\section{Discussion}

In this large-scale population-based prospective cohort study, we found that both general and age-comparative SRH were significantly associated with an increased risk of first-ever stroke and recurrent stroke in Chinese adults. The magnitude of associations was similar in predicting hemorrhagic and ischemic stroke, yet stronger in predicting fatal than non-fatal stroke. All associations were independent of various well-established stroke risk factors.

Though recommended as a key measure of cardiovascular health in disease surveillance, ${ }^{22}$ the association between SRH and incident stroke was not extensively investigated. In several studies in US and European populations, ${ }^{13-15}$ poor SRH was asso- ciated with a higher risk of first-ever stroke. However, they had relatively small sample size (ranged from 168 to 473 incident cases), and some studies combined the SRH measure into two categories (excellent/good vs. fair/poor). With regard to the association between SRH and recurrent stroke, two studies in UK populations did not find significant association, ${ }^{14,16}$ but the sample size was small: Mavaddat et al. ${ }^{14}$ identified 77 recurrent cases out of 434 stroke patients during 2 years' follow-up and Hillen et al. ${ }^{16}$ identified 66 recurrent cases out of 561 stroke patients during 5 years' follow-up. Therefore, our study is thus the largest prospective cohort study on this topic and the first of its kind in Asians. Participants in the CKB study were from 10 geographically distant regions, and had different socioeconomic background, dietary patterns, lifestyles, and disease profiles. Therefore, we believe that our study provides compelling evidence on the association between SRH and incident stroke.

Our study is the first prospective study on the association between SRH and different subtypes of stroke, and we found similar magnitudes of the associations for hemorrhagic and ischemic stroke. Although the pathophysiology of the two stroke subtype is different, they share similar risk factors that can be perceived by individuals, such as obesity, hypertension, smoking, and old age. ${ }^{23}$ We also investigated the relations of $\mathrm{SRH}$ with fatal and nonfatal stroke. Our results of non-fatal stroke were similar with two previous studies. ${ }^{13,14}$ No study has specifically examined the association between general SRH and fatal stroke, while some studies reported inconsistent findings with stroke mortality. 6,14,24 Two small studies in European populations did not find significant association between SRH 

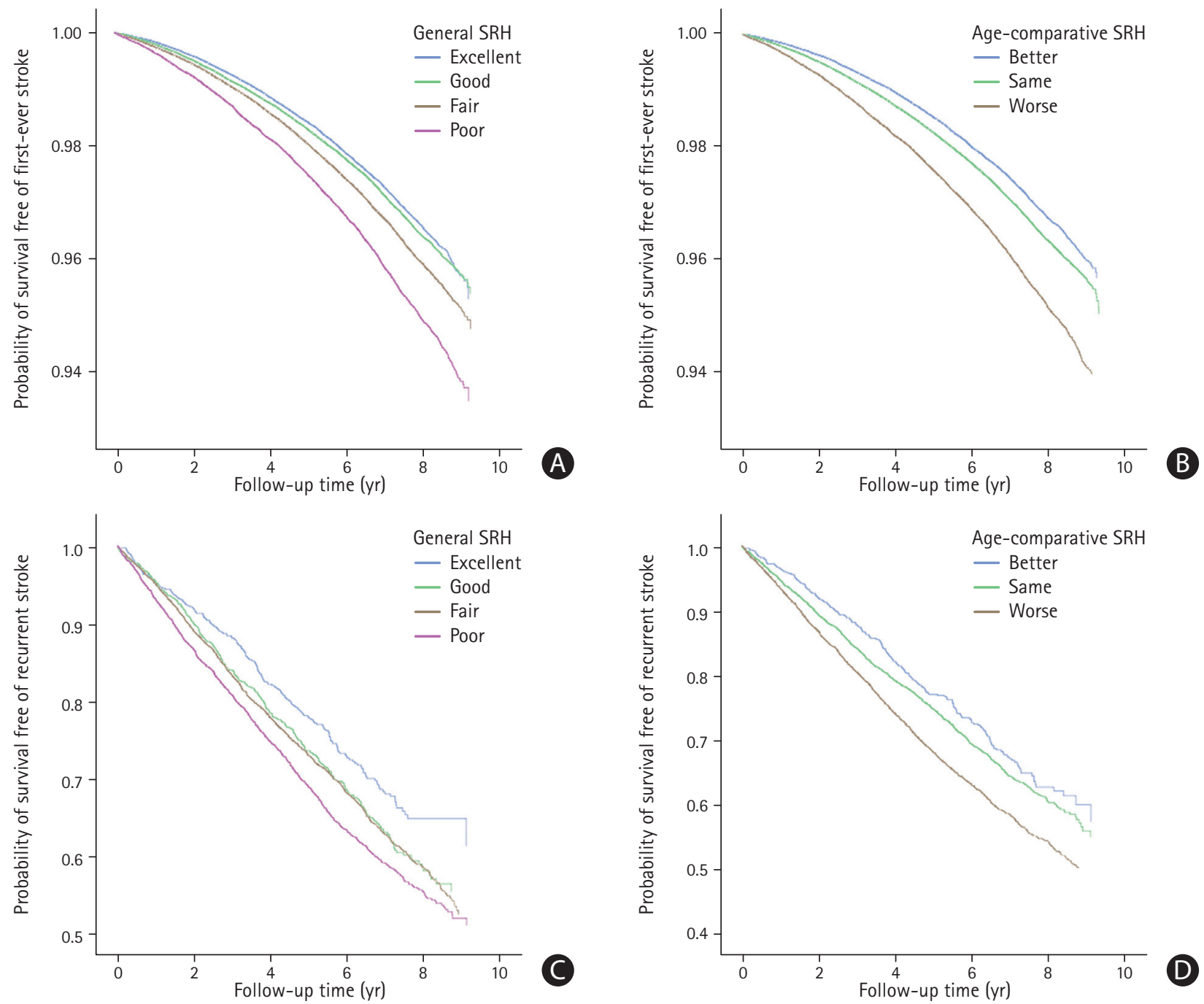

Figure 1. Survival and recurrence-free curves for participants according to self-rated health (SRH) categories. (A) First-ever stroke-free survival curves stratified by general SRH. (B) First-ever stroke-free survival curves stratified by age-comparative SRH. (C) Recurrence-free survival curves stratified by general SRH. (D) Recurrence-free survival curves stratified by age-comparative SRH. All survival curves were stratified by age (5 years intervals), sex, region (10 areas) and adjusted for age (continuous), marital status, education, annual household income, occupation, healthcare coverage, housing condition, menopausal status, sleep problems, cigarette smoking, alcohol drinking, physical activity (continuous), body mass index (continuous), family history of stroke, presence of baseline major depressive episodes, diabetes, hypertension, and other prevalent diseases (yes, no). The categories and definitions of all categorical variables were illustrated in the 'Covariates' section of the Methods.

and stroke mortality, ${ }^{6,14}$ while a large study in US adults $(n=689,710)$ reported a significant association (HR, $2.12 \mathrm{com}-$ paring poor with excellent SRH; $95 \% \mathrm{Cl}, 1.76$ to 2.56$).{ }^{24}$ The two European studies were also conducted in elderly populations (mean age, 74.1 and 76.2 years old), ${ }^{6,14}$ while the US study ${ }^{24}$ and our study were done in much younger participants (mean age, 44.4 and 51.0 years old). It was reported that the elders tend to rate their health more positively than their young counterparts; thus, SRH was a stronger predictor of mortality in younger than in older age groups. ${ }^{25}$

In addition to general SRH, we also identified significant associations between age-comparative SRH and stroke risk. It was argued that the general SRH question was mainly related with health terms including function, youth, habits, and etc., and the age-comparative question was further connected to social performance, income, profession, and personal achievement; thus, the two measures may not be used interchangeably. ${ }^{26}$ Our findings are consistent with two prior studies which also reported significant association between age-comparative SRH and stroke mortality. ${ }^{6,9}$

The associations between general SRH, age-comparative $\mathrm{SRH}$, and stroke risk may be explained by several reasons. First, both general and age-comparative SRH are integrative assessment of overall health based on one's own perception on his or her objective health condition such as comorbidity, ${ }_{1}^{27,28}$ disabili$\mathrm{ty}_{1}{ }^{29,30}$ and abnormal laboratory test results including hyperlip- 


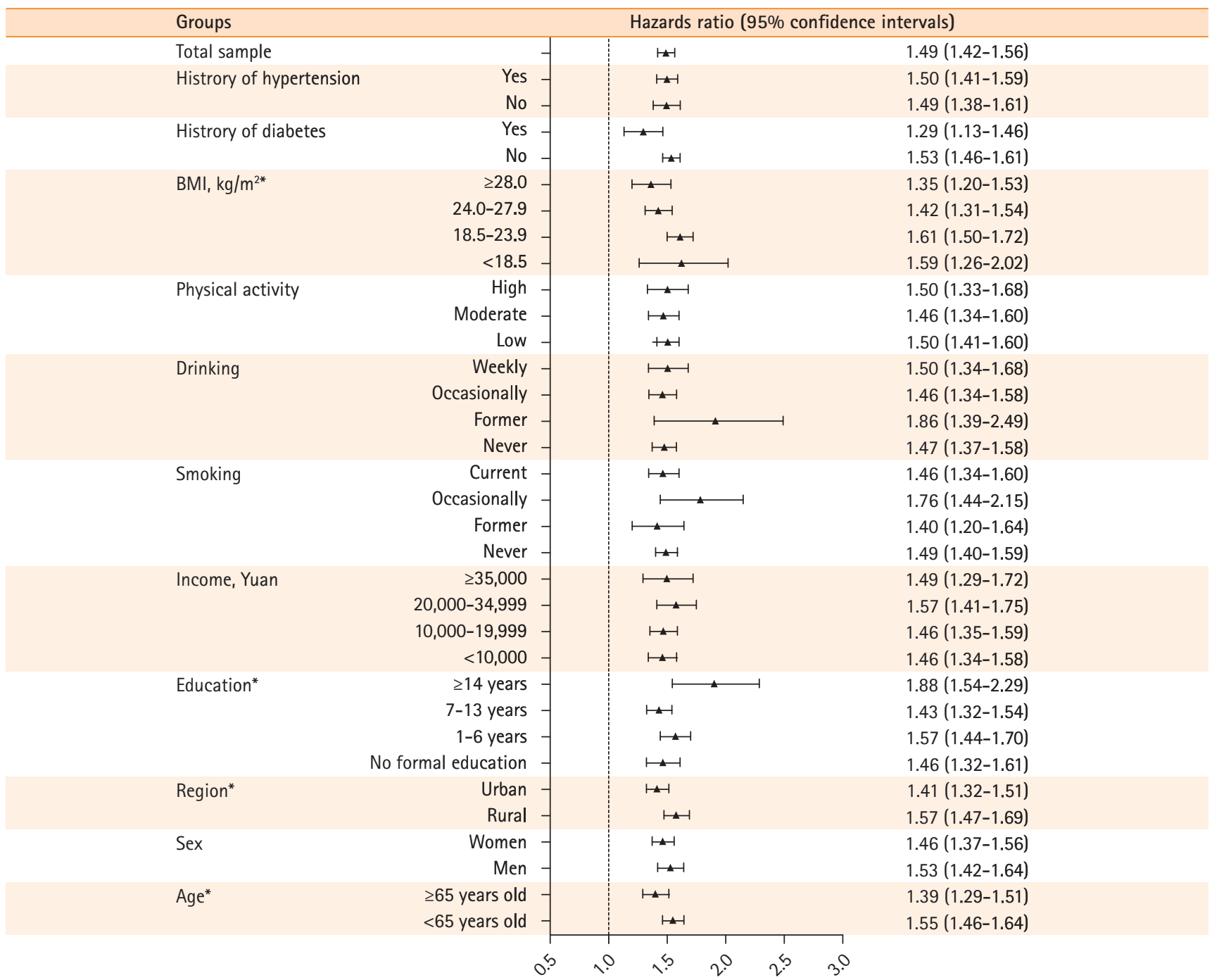

Figure 2. Stratified analysis: poor versus excellent general self-rated health and risk of first-ever stroke. The hazard ratios and 95\% confidence intervals were calculated after stratification by age ( 5 years intervals), sex, region (10 areas) and adjustment for age (continuous), marital status, education, annual household income, occupation, healthcare coverage, housing condition, menopausal status, sleep problems, cigarette smoking, alcohol drinking, physical activity (continuous), body mass index (BMI) (continuous), family history of stroke, presence of baseline major depressive episodes, diabetes, hypertension, and other prevalent diseases (yes, no). The categories and definitions of all categorical variables were illustrated in the 'Covariates' section of the Methods. ${ }^{*} P_{\text {interaction }}<0.05$.

idemia, hypertension, and hyperglycemia. ${ }^{27,31}$ These health conditions reflect current overall health status and are predictive factors for future disease risk. Second, psychological factors such as depression and anxiety are not only reported to be determinants of $\mathrm{SRH}^{27-29}$ but also significant risk factors for stroke. ${ }^{32,33}$ Third, inflammation and genetic polymorphism may also play a role. In two recent studies, ${ }^{31,34}$ poorer SRH was found to be significantly associated with elevated C-reactive protein independent of depression, neuroticism and objective health condition. According to a recent genome-wide association study of SRH among 111,749 participants from the UK Biobank study, ${ }_{1}^{35}$ several genetic variants were found to be associated with both SRH and large vessel stroke.
Our study was a prospective population-based cohort study, and comprehensive health-related data collected at baseline allowing us to adjust for many covariates in statistical models. Additionally, our study was the first to examine the association between SRH measures and stroke subtypes, also the first to investigate the relationship of age-comparative SRH with risk of stroke morbidity. The study has several limitations as well. First, inaccurate responses to the questions due to poor understanding might exist. In our study, participants were from 10 geographically distant regions with different demographic and culture backgrounds, which might influence their choices of the answers. However, in stratified analyses, the associations were observed in all subgroups. Second, reverse causality bias was possi- 
ble. However, we have excluded participants who died or developed stroke in the first 2 years after recruitment, positive associations persisted. Third, the confounding effect of objective health status may not be fully controlled in analyses. However, after excluding participants with cancer, CHD, and rheumatic heart disease in all analysis, and further exclusion of those with 13 chronic conditions in the sensitivity analyses, the associations remained significant. Finally, the severity of stroke, which might confound the association between SRH measures and stroke recurrence, was not measured in our study. Residual confounding due to factors such as air pollution, neuroticism, or anxiety might still exist, but not substantially change the results.

\section{Conclusions}

In our study, both general and age-comparative SRH were found to be independent predictors of incident stroke in Chinese, regardless of stroke subtypes or categories. Our findings suggest that on top of traditional risk factors of stroke, the two underutilized SRH measures may provide additional value on prediction of incident stroke. Healthcare providers in communities and physicians providing clinical care may use these simple, subjective, self-perceived questions to identify high-risk populations for prevention and intervention. The two measures of SRH may also be useful for public health practitioners, especially for those working in resource-limited settings. Nevertheless, whether the two SRH measures can be used in stroke risk prediction should be further confirmed in future studies, particularly for different populations.

\section{Supplementary materials}

Supplementary materials related to this article can be found online at https://doi.org/10.5853/jos.2017.01732.

\section{Disclosure}

The authors have no financial conflicts of interest.

\section{Acknowledgments}

The chief acknowledgment is to the participants, the project staff, and the China National Centre for Disease Control and Prevention (CDC) and its regional offices for assisting with the fieldwork. We thank Judith Mackay in Hong Kong; Yu Wang, Gonghuan Yang, Zhengfu Qiang, Lin Feng, Maigeng Zhou, Wenhua Zhao, and Yan Zhang in China CDC; Lingzhi Kong, Xiucheng $Y u$, and Kun Li in the Chinese Ministry of Health; and
Sarah Clark, Martin Radley, Mike Hill, Hongchao Pan, and Jill Boreham in the Clinical Trial Service Unit \& Epidemiological Studies Unit, Oxford, for assisting with the design, planning, organization, and conduct of the study.

Members of the China Kadoorie Biobank collaborative group are as follows.

International Steering Committee: Junshi Chen, Zhengming Chen (PI), Rory Collins, Liming Li (PI), and Richard Peto.

International Co-ordinating Centre, Oxford: Daniel Avery, Ruth Boxall, Derrick Bennett, Yumei Chang, Yiping Chen, Zhengming Chen, Robert Clarke, Huaidong Du, Simon Gilbert, Alex Hacker, Mike Hill, Michael Holmes, Andri lona, Christiana Kartsonaki, Rene Kerosi, Ling Kong, Om Kurmi, Garry Lancaster, Sarah Lewington, Kuang Lin, John McDonnell, lona Millwood, Qunhua Nie, Jayakrishnan Radhakrishnan, Sajjad Rafiq, Paul Ryder, Sam Sansome, Dan Schmidt, Paul Sherliker, Rajani Sohoni, Becky Stevens, lain Turnbull, Robin Walters, Jenny Wang, Lin Wang, Neil Wright, Ling Yang, and Xiaoming Yang.

National Co-ordinating Centre, Beijing: Zheng Bian, Yu Guo, Xiao Han, Can Hou, Jun Lv, Pei Pei, Yunlong Tan, and Canqing Yu.

Ten Regional Co-ordinating Centres: Qingdao CDC (Zengchang Pang, Ruqin Gao, Shanpeng Li, Shaojie Wang, Yongmei Liu, Ranran Du, Yajing Zang, Liang Cheng, Xiaocao Tian, Hua Zhang, Yaoming Zhai, Feng Ning, Xiaohui Sun, and Feifei Li); Licang CDC (Silu Lv, Junzheng Wang, and Wei Hou); Heilongjiang Provincial CDC (Mingyuan Zeng, Ge Jiang, and Xue Zhou); Nangang CDC (Liqiu Yang, Hui He, Bo Yu, Yanjie Li, Qinai Xu, Quan Kang, and Ziyan Guo); Hainan Provincial CDC (Dan Wang, Ximin Hu, Hongmei Wang, Jinyan Chen, Yan Fu, Zhenwang Fu, and Xiaohuan Wang); Meilan CDC (Min Weng, Zhendong Guo, Shukuan Wu, Yilei Li, Huimei Li, and Zhifang Fu); Jiangsu Provincial CDC (Ming Wu, Yonglin Zhou, Jinyi Zhou, Ran Tao, Jie Yang, and Jian Su); Suzhou CDC (Fang liu, Jun Zhang, Yihe Hu, Yan Lu, Liangcai Ma, Aiyu Tang, Shuo Zhang, Jianrong Jin, and Jingchao Liu); Guangxi Provincial CDC (Zhenzhu Tang, Naying Chen, and Ying Huang); Liuzhou CDC (Mingqiang Li, Jinhuai Meng, Rong Pan, Qilian Jiang, Jian Lan, Yun Liu, Liuping Wei, Liyuan Zhou, Ningyu Chen Ping Wang, Fanwen Meng, Yulu Qin, and Sisi Wang); Sichuan Provincial CDC (Xianping Wu, Ningmei Zhang, Xiaofang Chen, and Weiwei Zhou); Pengzhou CDC (Guojin Luo, Jianguo Li, Xiaofang Chen, Xunfu Zhong, Jiaqiu Liu, and Qiang Sun); Gansu Provincial CDC (Pengfei Ge, Xiaolan Ren, and Caixia Dong); Maiji CDC (Hui Zhang, Enke Mao, Xiaoping Wang, Tao Wang, and Xi Zhang); Henan Provincial CDC (Ding Zhang, Gang Zhou, Shixian Feng, Liang Chang, and Lei Fan); Huixian CDC (Yulian Gao, Tianyou He, Huarong Sun, Pan He, Chen Hu, Xukui Zhang, Huifang $W u$, and Pan He); Zhejiang Provincial CDC (Min Yu, Ruying 
$\mathrm{Hu}$, and Hao Wang); Tongxiang CDC (Yijian Qian, Chunmei Wang, Kaixu Xie, Lingli Chen, Yidan Zhang, Dongxia Pan, and Qijun Gu); Hunan Provincial CDC (Yuelong Huang, Biyun Chen, Li Yin, Huilin Liu, Zhongxi Fu, and Qiaohua Xu); and Liuyang CDC (Xin Xu, Hao Zhang, Huajun Long, Xianzhi Li, Libo Zhang, and Zhe Qiu).

This work was supported by the National Key Research and Development Program of China (2016YFC0900500, 2016YFC0900501, 2016YFC0900504, 2017YFC0907500, and 2017YFC0907504) and National Natural Science Foundation of China (81390540, 81390541, 81390542, 81202266, and 81230069). The China Kadoorie Biobank baseline survey and the first re-survey were supported by a grant from the Kadoorie Charitable Foundation in Hong Kong. The long-term follow-up is supported by grants from the UK Wellcome Trust (202922/Z/16/ Z, 088158/Z/09/Z, 104085/Z/14/Z) and Chinese Ministry of Science and Technology (2011BAI09B01). The funders had no role in the study design, data collection, data analysis and interpretation, writing of the report, or the decision to submit the article for publication.

\section{References}

1. Wang Z, Hu S, Sang S, Luo L, Yu C. Age-period-cohort analysis of stroke mortality in China: data from the global burden of disease study 2013. Stroke 2017;48:271-275.

2. Yang G, Wang $Y$, Zeng $Y$, Gao GF, Liang $X$, Zhou $M$, et al. Rapid health transition in China, 1990-2010: findings from the Global Burden of Disease Study 2010. Lancet 2013;381:19872015.

3. Wang $W_{\text {, Jiang }} B_{\text {, Sun }} H_{1}, R u X_{\text {, Sun }}$, Wang $_{L}$, et al. Prevalence, incidence, and mortality of stroke in China: results from a nationwide population-based survey of 480687 adults. Circulation 2017;135:759-771.

4. Wang J, An Z, Li B, Yang L, Tu J, Gu H, et al. Increasing stroke incidence and prevalence of risk factors in a low-income Chinese population. Neurology 2015;84:374-381.

5. Guo Y, Wang H, Tian Y, Wang Y, Lip GY. Multiple risk factors and ischaemic stroke in the elderly Asian population with and without atrial fibrillation. An analysis of 425,600 Chinese individuals without prior stroke. Thromb Haemost 2016;115:184192.

6. Fernández-Ruiz M, Guerra-Vales JM, Trincado R, Fernández $R$, Medrano MJ, Villarejo $A$, et al. The ability of self-rated health to predict mortality among community-dwelling elderly individuals differs according to the specific cause of death: data from the NEDICES cohort. Gerontology 2013;59:368-377.
7. Ganna A, Ingelsson E. 5 Year mortality predictors in 498,103 UK Biobank participants: a prospective population-based study. Lancet 2015;386:533-540.

8. Barger SD, Cribbet MR, Muldoon MF. Participant-reported health status predicts cardiovascular and all-cause mortality independent of established and nontraditional biomarkers: evidence from a representative US Sample. J Am Heart Assoc 2016;5:e003741.

9. Shen C, Schooling CM, Chan WM, Zhou JX, Johnston JM, Lee SY, et al. Self-rated health and mortality in a prospective Chinese elderly cohort study in Hong Kong. Prev Med 2014;67: 112-118.

10. Mavaddat N, Parker RA, Sanderson S, Mant J, Kinmonth AL. Relationship of self-rated health with fatal and non-fatal outcomes in cardiovascular disease: a systematic review and meta-analysis. PLoS One 2014;9:e103509.

11. van der Linde RM, Mavaddat N, Luben R, Brayne C, Simmons RK, Khaw KT, et al. Self-rated health and cardiovascular disease incidence: results from a longitudinal population-based cohort in Norfolk, UK. PLoS One 2013;8:e65290.

12. Kaplan GA, Goldberg DE, Everson $S A$, Cohen RD, Salonen $R$, Tuomilehto J, et al. Perceived health status and morbidity and mortality: evidence from the Kuopio ischaemic heart disease risk factor study. Int J Epidemiol 1996;25:259-265.

13. Latham K, Peek CW. Self-rated health and morbidity onset among late midlife U.S. adults. J Gerontol B Psychol Sci Soc Sci 2013;68:107-116.

14. Mavaddat $N$, van der Linde $R$, Parker R, Savwa G, Kinmonth AL, Brayne $C$, et al. Relationship of self-rated health to stroke incidence and mortality in older individuals with and without a history of stroke: a longitudinal study of the MRC Cognitive Function and Ageing (CFAS) population. PLoS One 2016;11: e0150178.

15. Emmelin M, Weinehall L, Stegmayr B, Dahlgren L, Stenlund $H$, Wall S. Self-rated ill-health strengthens the effect of biomedical risk factors in predicting stroke, especially for men: an incident case referent study. J Hypertens 2003;21:887-896.

16. Hillen $T$, Davies $S$, Rudd AG, Kieselbach $T$, Wolfe CD. Self ratings of health predict functional outcome and recurrence free survival after stroke. J Epidemiol Community Health 2003;57:960-966.

17. Chen $Z$, Chen J, Collins R, Guo Y, Peto R, Wu F, et al. China Kadoorie Biobank of 0.5 million people: survey methods, baseline characteristics and long-term follow-up. Int J Epidemiol 2011;40:1652-1666.

18. World Health Organization. The WHO STEPwise approach to stroke surveillance. http://www.who.int/chp/steps/stroke/ manual/en/. Accessed April 6, 2018. 
19. Bragg F, Li L, Yang L, Guo Y, Chen Y, Bian Z, et al. Risks and population burden of cardiovascular diseases associated with diabetes in china: a prospective study of 0.5 million adults. PLoS Med 2016;13:e1002026.

20. Lewington $S$, Lacey $B$, Clarke $R, G$ Go $Y$, Kong $X L$, Yang $L$, et al. The burden of hypertension and associated risk for cardiovascular mortality in China. JAMA Intern Med 2016;176:524532.

21. Mezuk B, Chen $Y, Y u$ C, Guo Y, Bian Z, Collins R, et al. Depression, anxiety, and prevalent diabetes in the Chinese population: findings from the China Kadoorie Biobank of 0.5 million people. J Psychosom Res 2013;75:511-517.

22. Rumsfeld JS, Alexander KP, Goff DC Jr, Graham MM, Ho PM, Masoudi FA, et al. Cardiovascular health: the importance of measuring patient-reported health status: a scientific statement from the American Heart Association. Circulation 2013;127:2233-2249.

23. Boehme AK, Esenwa C, Elkind MS. Stroke risk factors, genetics, and prevention. Circ Res 2017;120:472-495.

24. Benjamins MR, Hummer RA, Eberstein IW, Nam CB. Self-reported health and adult mortality risk: an analysis of cause-specific mortality. Soc Sci Med 2004;59:1297-1306.

25. Jylhä M. What is self-rated health and why does it predict mortality? Towards a unified conceptual model. Soc Sci Med 2009;69:307-316.

26. Waller $G$, Thalén $P$, Janlert $U$, Hamberg $K$, Forssén A. A cross-sectional and semantic investigation of self-rated health in the northern Sweden MONICA-study. BMC Med Res Methodol 2012;12:154.

27. Haseli-Mashhadi N, Pan A, Ye X, Wang J, Qi Q, Liu Y, et al. Self-rated health in middle-aged and elderly Chinese: distribution, determinants and associations with cardio-metabolic risk factors. BMC Public Health 2009;9:368.

28. Mavaddat N, Valderas JM, van der Linde R, Khaw KT, Kinmonth AL. Association of self-rated health with multimorbidity, chronic disease and psychosocial factors in a large middle-aged and older cohort from general practice: a cross-sectional study. BMC Fam Pract 2014;15:185.

29. Stanojevic Jerkovic O, Sauliune S, Šumskas L, Birt CA, Kersnik $J$. Determinants of self-rated health in elderly populations in urban areas in Slovenia, Lithuania and UK: findings of the EURO-URHIS 2 survey. Eur J Public Health 2017;27(suppl_2):74-79.

30. Brenowitz WD, Hubbard RA, Crane PK, Gray SL, Zaslavsky O, Larson EB. Longitudinal associations between self-rated health and performance-based physical function in a population-based cohort of older adults. PLoS One 2014;9:e111761.

31. Shanahan L, Bauldry S, Freeman J, Bondy CL. Self-rated health and C-reactive protein in young adults. Brain Behav Immun 2014;36:139-146.

32. Pan A, Sun O, Okereke OI, Rexrode KM, Hu FB. Depression and risk of stroke morbidity and mortality: a meta-analysis and systematic review. JAMA 2011;306:1241-1249.

33. Emdin CA, Odutayo A, Wong CX, Tran J, Hsiao AJ, Hunn BH. Meta-analysis of anxiety as a risk factor for cardiovascular disease. Am J Cardiol 2016;118:511-519.

34. Christian LM, Glaser R, Porter $K$, Malarkey WB, Beversdorf $D$, Kiecolt-Glaser JK. Poorer self-rated health is associated with elevated inflammatory markers among older adults. Psychoneuroendocrinology 2011;36:1495-1504.

35. Harris SE, Hagenaars SP, Davies G1, David Hill W, Liewald DCM, Ritchie SJ, et al. Molecular genetic contributions to self-rated health. Int J Epidemiol 2017;46:994-1009. 
Supplementary Table 1. Baseline characteristics according to age-comparative self-rated health status

\begin{tabular}{|c|c|c|c|c|}
\hline \multirow[b]{2}{*}{ Characteristic } & \multirow[b]{2}{*}{ Total $(n=471,551)$} & \multicolumn{3}{|c|}{ Age-comparative self-rated health } \\
\hline & & $\begin{array}{c}\text { Better } \\
(n=90,738)\end{array}$ & $\begin{array}{c}\text { Same } \\
(n=309,022)\end{array}$ & $\begin{array}{c}\text { Worse } \\
(n=71,791)\end{array}$ \\
\hline \multicolumn{5}{|l|}{ Sociodemographic factor } \\
\hline Age, mean \pm SD (yr) & $50.9 \pm 10.5$ & $50.8 \pm 10.7$ & $50.9 \pm 10.5$ & $51.4 \pm 10.5$ \\
\hline Female sex (\%) & 58.9 & 54.0 & 58.8 & 65.6 \\
\hline Married (\%) & 91.0 & 91.1 & 91.4 & 89.0 \\
\hline No formal education (\%) & 18.6 & 14.3 & 18.6 & 24.1 \\
\hline Annual household income $\geq 35,000$ Yuan (\%) & 17.8 & 20.3 & 18.3 & 12.7 \\
\hline Unemployed or not stated (\%) & 14.1 & 10.7 & 14.0 & 18.8 \\
\hline Healthcare coverage (\%) & 82.2 & 84.2 & 82.5 & 78.1 \\
\hline House/apartment owning (\%) & 44.7 & 39.3 & 47.7 & 38.9 \\
\hline Rural area $(\%)$ & 57.7 & 45.4 & 61.0 & 58.8 \\
\hline \multicolumn{5}{|l|}{ Lifestyle factor } \\
\hline Current regular smoker $(\%)$ & 26.9 & 30.2 & 26.8 & 23.1 \\
\hline Weekly alcohol drinker (\%) & 15.3 & 20.5 & 14.8 & 10.5 \\
\hline Physical activity, mean \pm SD (MET-hr/day) & $21.7 \pm 13.9$ & $21.8 \pm 13.7$ & $22.0 \pm 14.0$ & $20.3 \pm 13.7$ \\
\hline Sleep problems (\%) & 16.3 & 11.3 & 14.7 & 29.5 \\
\hline \multicolumn{5}{|l|}{ Personal/family medical history } \\
\hline $\mathrm{BMI}$, mean $\pm \mathrm{SD}\left(\mathrm{kg} / \mathrm{m}^{2}\right)$ & $23.6 \pm 3.4$ & $24.0 \pm 3.2$ & $23.5 \pm 3.3$ & $23.3 \pm 3.7$ \\
\hline Postmenopausal (women only) (\%) & 50.4 & 47.0 & 49.9 & 55.7 \\
\hline Family history of stroke (\%) & 17.7 & 19.9 & 16.5 & 19.7 \\
\hline Prevalent diabetes (\%) & 5.3 & 3.7 & 4.8 & 9.6 \\
\hline Prevalent hypertension (\%) & 32.5 & 29.4 & 32.7 & 35.6 \\
\hline Prevalent major depression (\%) & 0.6 & 0.3 & 0.4 & 1.8 \\
\hline Other prevalent medical conditions ( $\%)$ & 22.8 & 18.4 & 19.7 & 35.3 \\
\hline
\end{tabular}

Two-sided $P$-values were derived from ANOVA for continuous variables and from the chi-square test for categorical variables, all $P$-values comparing the difference between age-comparative self-rated health status groups $<0.001$.

$\mathrm{SD}$, standard deviation; MET, metabolic equivalent; BMI, body mass index. 
Supplementary Table 2. Stratified analysis: association of general self-rated health status with risk of first-ever stroke

\begin{tabular}{|c|c|c|c|c|}
\hline \multirow{2}{*}{ Subgroup } & \multirow{2}{*}{ Cases/person-years } & \multicolumn{2}{|c|}{$\mathrm{HR}(95 \% \mathrm{Cl})$} & \multirow{2}{*}{$P$ for interaction } \\
\hline & & Model $1^{*}$ & Model $2^{+}$ & \\
\hline Age & & & & 0.01 \\
\hline \multicolumn{5}{|l|}{$<65$ years old } \\
\hline Excellent & $2,652 / 563,348$ & 1.00 & 1.00 & \\
\hline Good & $4,269 / 905,358$ & $1.09(1.04-1.15)$ & $1.07(1.02-1.13)$ & \\
\hline Fair & $8,438 / 1,277,830$ & $1.31(1.26-1.37)$ & $1.23(1.18-1.29)$ & \\
\hline Poor & $2,333 / 266,096$ & $1.77(1.67-1.87)$ & $1.55(1.46-1.64)$ & \\
\hline \multicolumn{5}{|l|}{$\geq 65$ years old } \\
\hline Excellent & $1,552 / 61,542$ & 1.00 & 1.00 & \\
\hline Good & $2,218 / 106,030$ & $1.01(0.94-1.07)$ & $0.99(0.93-1.06)$ & \\
\hline Fair & $4,894 / 199,043$ & $1.17(1.10-1.24)$ & $1.12(1.06-1.19)$ & \\
\hline Poor & $1,306 / 45,558$ & $1.48(1.37-1.60)$ & $1.39(1.29-1.51)$ & \\
\hline Sex & & & & 0.18 \\
\hline \multicolumn{5}{|l|}{ Men } \\
\hline Excellent & $2,211 / 287,366$ & 1.00 & 1.00 & \\
\hline Good & $3,355 / 424,806$ & $1.08(1.02-1.14)$ & $1.06(1.00-1.12)$ & \\
\hline Fair & $6,085 / 566,892$ & $1.27(1.21-1.33)$ & $1.20(1.14-1.27)$ & \\
\hline Poor & $1,429 / 102,599$ & $1.69(1.57-1.81)$ & $1.53(1.42-1.64)$ & \\
\hline \multicolumn{5}{|l|}{ Women } \\
\hline Excellent & $1,993 / 337,524$ & 1.00 & 1.00 & \\
\hline Good & 3,132/586,582 & $1.04(0.98-1.10)$ & $1.02(0.96-1.08)$ & \\
\hline Fair & 7,247/909,981 & $1.24(1.18-1.30)$ & $1.17(1.12-1.24)$ & \\
\hline Poor & $2,210 / 209,055$ & $1.62(1.53-1.73)$ & $1.46(1.37-1.56)$ & \\
\hline Administrative region & & & & 0.03 \\
\hline \multicolumn{5}{|l|}{ Rural } \\
\hline Excellent & $1,499 / 276,278$ & 1.00 & 1.00 & \\
\hline Good & $3,916 / 650,391$ & $1.11(1.04-1.18)$ & $1.09(1.03-1.16)$ & \\
\hline Fair & $6,877 / 848,018$ & $1.28(1.20-1.35)$ & $1.23(1.16-1.30)$ & \\
\hline Poor & $2,221 / 202,093$ & $1.72(1.61-1.84)$ & $1.57(1.47-1.69)$ & \\
\hline \multicolumn{5}{|l|}{ Urban } \\
\hline Excellent & $2,705 / 348,611$ & 1.00 & 1.00 & \\
\hline Good & $2,571 / 360,997$ & $1.02(0.97-1.08)$ & $1.01(0.95-1.06)$ & \\
\hline Fair & $6,455 / 628,855$ & $1.24(1.19-1.30)$ & $1.18(1.12-1.23)$ & \\
\hline Poor & $1,418 / 109,561$ & $1.58(1.48-1.69)$ & $1.41(1.32-1.51)$ & \\
\hline Education & & & & 0.02 \\
\hline \multicolumn{5}{|l|}{ No formal education } \\
\hline Excellent & $706 / 94,554$ & 1.00 & 1.00 & \\
\hline Good & $1,683 / 212,177$ & $1.15(1.05-1.26)$ & $1.13(1.03-1.23)$ & \\
\hline Fair & $3,020 / 259,727$ & $1.29(1.19-1.41)$ & $1.24(1.14-1.35)$ & \\
\hline Poor & $1,058 / 76,866$ & $1.58(1.43-1.75)$ & $1.46(1.32-1.61)$ & \\
\hline \multicolumn{5}{|l|}{ 1-6 Years } \\
\hline Excellent & $1,175 / 163,094$ & 1.00 & 1.00 & \\
\hline Good & $2,238 / 327,233$ & $1.05(0.98-1.13)$ & $1.04(0.96-1.11)$ & \\
\hline Fair & 4,819/494,883 & $1.23(1.15-1.31)$ & $1.18(1.11-1.26)$ & \\
\hline Poor & 1,338/110,533 & $1.71(1.57-1.85)$ & $1.57(1.44-1.70)$ & \\
\hline
\end{tabular}


Supplementary Table 2. Continued

\begin{tabular}{|c|c|c|c|c|}
\hline \multirow{2}{*}{ Subgroup } & \multirow{2}{*}{ Cases/person-years } & \multicolumn{2}{|c|}{$\mathrm{HR}(95 \% \mathrm{Cl})$} & \multirow{2}{*}{ Pfor interactior } \\
\hline & & Model $1^{*}$ & Model $2^{+}$ & \\
\hline \multicolumn{5}{|l|}{ 7-13 Years } \\
\hline Excellent & $1,857 / 309,761$ & 1.00 & 1.00 & \\
\hline Good & $2,205 / 423,699$ & $1.01(0.94-1.07)$ & $0.99(0.93-1.05)$ & \\
\hline Fair & $4,706 / 645,620$ & $1.24(1.17-1.31)$ & $1.17(1.11-1.24)$ & \\
\hline Poor & $1,105 / 115,223$ & $1.62(1.50-1.74)$ & $1.43(1.32-1.54)$ & \\
\hline \multicolumn{5}{|l|}{$\geq 14$ Years } \\
\hline Excellent & $466 / 570,480$ & 1.00 & 1.00 & \\
\hline Good & $361 / 480,279$ & $1.06(0.92-1.22)$ & $1.05(0.92-1.21)$ & \\
\hline Fair & $733 / 760,645$ & $1.34(1.18-1.18)$ & $1.26(1.11-1.42)$ & \\
\hline Poor & $138 / 90,033$ & $2.10(1.72-2.55)$ & $1.88(1.54-2.29)$ & \\
\hline Annually household income & & & & 0.26 \\
\hline \multicolumn{5}{|l|}{$<10,000$ Yuan } \\
\hline Excellent & $1,097 / 137,948$ & 1.00 & 1.00 & \\
\hline Good & 1,993/267,558 & $1.02(0.95-1.10)$ & $1.01(0.94-1.09)$ & \\
\hline Fair & $4,230 / 440,900$ & $1.22(1.14-1.31)$ & $1.19(1.11-1.27)$ & \\
\hline Poor & $1,650 / 142,713$ & $1.57(1.45-1.70)$ & $1.46(1.34-1.58)$ & \\
\hline \multicolumn{5}{|l|}{ 10,000-19,999 Yuan } \\
\hline Excellent & $1,338 / 166797$ & 1.00 & 1.00 & \\
\hline Good & $2,057 / 283519$ & $1.05(0.98-1.13)$ & $1.03(0.96-1.10)$ & \\
\hline Fair & $4,336 / 455769$ & $1.21(1.13-1.29)$ & $1.14(1.07-1.22)$ & \\
\hline Poor & $1,117 / 88313$ & $1.64(1.51-1.78)$ & $1.46(1.35-1.59)$ & \\
\hline \multicolumn{5}{|l|}{ 20,000-34,999 Yuan } \\
\hline Excellent & $1,052 / 172,835$ & 1.00 & 1.00 & \\
\hline Good & $1,405 / 259,438$ & $1.07(0.99-1.17)$ & $1.06(0.97-1.15)$ & \\
\hline Fair & 2,919/357,072 & $1.26(1.17-1.35)$ & 1.19 (1.10-1.28) & \\
\hline Poor & $594 / 50,429$ & $1.77(1.60-1.97)$ & $1.57(1.41-1.75)$ & \\
\hline \multicolumn{5}{|l|}{$\geq 35,000$ Yuan } \\
\hline Excellent & $744 / 147,310$ & 1.00 & 1.00 & \\
\hline Good & $1,032 / 200,872$ & $1.12(1.02-1.24)$ & $1.11(1.01-1.22)$ & \\
\hline Fair & $1,847 / 223,133$ & $1.38(1.27-1.51)$ & $1.31(1.19-1.43)$ & \\
\hline Poor & 278/30,198 & $1.66(1.44-1.92)$ & $1.49(1.29-1.72)$ & \\
\hline Cigarette smoking & & & & 0.84 \\
\hline \multicolumn{5}{|l|}{ Never } \\
\hline Excellent & $2,189 / 365,030$ & 1.00 & 1.00 & \\
\hline Good & $3,422 / 618,576$ & $1.05(1.00-1.11)$ & $1.03(0.98-1.09)$ & \\
\hline Fair & $7,810 / 951,585$ & 1.25 (1.19-1.32) & $1.19(1.13-1.25)$ & \\
\hline Poor & $2,173 / 203,610$ & $1.66(1.56-1.76)$ & $1.49(1.40-1.59)$ & \\
\hline \multicolumn{5}{|l|}{ Former } \\
\hline Excellent & $430 / 33,326$ & 1.00 & 1.00 & \\
\hline Good & $566 / 53,726$ & $0.93(0.81-1.05)$ & $0.91(0.80-1.04)$ & \\
\hline Fair & 1,126/76,128 & $1.14(1.02-1.28)$ & $1.09(0.97-1.22)$ & \\
\hline Poor & $345 / 18,821$ & $1.52(1.30-1.77)$ & $1.40(1.20-1.64)$ & \\
\hline \multicolumn{5}{|l|}{ Occasionally } \\
\hline Excellent & $230 / 37,473$ & 1.00 & 1.00 & \\
\hline
\end{tabular}


Supplementary Table 2. Continued

\begin{tabular}{|c|c|c|c|c|}
\hline \multirow{2}{*}{ Subgroup } & \multirow{2}{*}{ Cases/person-years } & \multicolumn{2}{|c|}{$\mathrm{HR}(95 \% \mathrm{Cl})$} & \multirow{2}{*}{$P$ for interactior } \\
\hline & & Model $1^{*}$ & Model $2^{+}$ & \\
\hline Good & $418 / 55,524$ & $1.21(1.02-1.42)$ & $1.18(1.00-1.39)$ & \\
\hline Fair & $765 / 84,760$ & $1.36(1.16-1.58)$ & $1.29(1.11-1.51)$ & \\
\hline Poor & $204 / 17,667$ & $1.89(1.55-2.30)$ & $1.76(1.44-2.15)$ & \\
\hline \multicolumn{5}{|l|}{ Current } \\
\hline Excellent & $1,355 / 189,061$ & 1.00 & 1.00 & \\
\hline Good & $2,081 / 283,562$ & $1.09(1.01-1.16)$ & $1.07(1.00-1.15)$ & \\
\hline Fair & $3,631 / 364,402$ & $1.27(1.19-1.35)$ & $1.20(1.13-1.28)$ & \\
\hline Poor & $917 / 71,556$ & $1.63(1.50-1.78)$ & $1.46(1.34-1.60)$ & \\
\hline Alcohol drinking & & & & 0.77 \\
\hline \multicolumn{5}{|l|}{ Never } \\
\hline Excellent & $1,572 / 250,324$ & 1.00 & 1.00 & \\
\hline Good & $2,629 / 459,511$ & $1.02(0.96-1.09)$ & $1.00(0.94-1.07)$ & \\
\hline Fair & $6,434 / 702,971$ & $1.24(1.17-1.31)$ & $1.18(1.11-1.25)$ & \\
\hline Poor & $1,885 / 156,670$ & $1.62(1.51-1.74)$ & $1.47(1.37-1.58)$ & \\
\hline \multicolumn{5}{|l|}{ Former } \\
\hline Excellent & $71 / 5,849$ & 1.00 & 1.00 & \\
\hline Good & $154 / 11,445$ & $1.24(0.93-1.66)$ & $1.22(0.91-1.62)$ & \\
\hline Fair & $393 / 24,701$ & $1.31(1.01-1.70)$ & $1.26(0.97-1.64)$ & \\
\hline Poor & $183 / 9,695$ & $1.96(1.47-2.62)$ & $1.86(1.39-2.49)$ & \\
\hline \multicolumn{5}{|l|}{ Occasionally } \\
\hline Excellent & $1526 / 234359$ & 1.00 & 1.00 & \\
\hline Good & $2315 / 351863$ & $1.08(1.01-1.15)$ & $1.06(0.99-1.13)$ & \\
\hline Fair & $4273 / 523762$ & $1.24(1.17-1.32)$ & $1.18(1.11-1.25)$ & \\
\hline Poor & 1091/103992 & $1.62(1.5-1.76)$ & $1.46(1.34-1.58)$ & \\
\hline \multicolumn{5}{|l|}{ Weekly } \\
\hline Excellent & $1,035 / 134,357$ & 1.00 & 1.00 & \\
\hline Good & 1,389/188,539 & $1.09(1.00-1.18)$ & $1.07(0.99-1.17)$ & \\
\hline Fair & $2,232 / 225,440$ & $1.28(1.18-1.38)$ & $1.21(1.12-1.30)$ & \\
\hline Poor & $480 / 41,297$ & $1.69(1.51-1.89)$ & $1.50(1.34-1.68)$ & \\
\hline Physical activity & & & & 0.93 \\
\hline \multicolumn{5}{|l|}{ Low } \\
\hline Excellent & $2,082 / 160,377$ & 1.00 & 1.00 & \\
\hline Good & $3,061 / 265,969$ & $1.06(1.01-1.13)$ & $1.05(0.99-1.11)$ & \\
\hline Fair & 7,429/503,983 & $1.27(1.21-1.34)$ & $1.22(1.16-1.28)$ & \\
\hline Poor & $2,125 / 117,495$ & $1.65(1.55-1.76)$ & $1.50(1.41-1.60)$ & \\
\hline \multicolumn{5}{|l|}{ Moderate } \\
\hline Excellent & $1,325 / 230,727$ & 1.00 & 1.00 & \\
\hline Good & 1,958/336,912 & $1.05(0.98-1.13)$ & $1.02(0.95-1.10)$ & \\
\hline Fair & 3,749/496,385 & $1.23(1.16-1.32)$ & $1.16(1.09-1.24)$ & \\
\hline Poor & $974 / 103,252$ & $1.64(1.50-1.79)$ & $1.46(1.34-1.60)$ & \\
\hline \multicolumn{5}{|l|}{ High } \\
\hline Excellent & $797 / 233,785$ & 1.00 & 1.00 & \\
\hline Good & $1,468 / 408,507$ & $1.05(0.96-1.15)$ & $1.04(0.95-1.14)$ & \\
\hline Fair & $2,154 / 476,506$ & $1.21(1.11-1.32)$ & $1.15(1.06-1.26)$ & \\
\hline
\end{tabular}


Supplementary Table 2. Continued

\begin{tabular}{|c|c|c|c|c|}
\hline \multirow{2}{*}{ Subgroup } & \multirow{2}{*}{ Cases/person-years } & \multicolumn{2}{|c|}{ HR (95\% Cl) } & \multirow{2}{*}{ Pfor interaction } \\
\hline & & Model $1^{*}$ & Model $2^{+}$ & \\
\hline Poor & $540 / 90,907$ & $1.65(1.47-1.85)$ & $1.50(1.33-1.68)$ & \\
\hline BMI & & & & 0.03 \\
\hline \multicolumn{5}{|l|}{$<18.5 \mathrm{~kg} / \mathrm{m}^{2}$} \\
\hline Excellent & $110 / 17,927$ & 1.00 & 1.00 & \\
\hline Good & $222 / 33,644$ & $1.10(0.87-1.39)$ & $1.09(0.86-1.37)$ & \\
\hline Fair & $638 / 71,607$ & $1.28(1.04-1.58)$ & $1.25(1.01-1.54)$ & \\
\hline Poor & $259 / 22,435$ & $1.64(1.30-2.08)$ & $1.59(1.26-2.02)$ & \\
\hline \multicolumn{5}{|l|}{$18.5-23.9 \mathrm{~kg} / \mathrm{m}^{2}$} \\
\hline Excellent & $1,769 / 322,794$ & 1.00 & 1.00 & \\
\hline Good & 2,981/535,202 & $1.07(1.01-1.13)$ & $1.05(0.99-1.12)$ & \\
\hline Fair & $6,178 / 786,225$ & $1.27(1.20-1.34)$ & $1.21(1.15-1.28)$ & \\
\hline Poor & $1,701 / 163,605$ & $1.76(1.64-1.89)$ & $1.61(1.50-1.72)$ & \\
\hline \multicolumn{5}{|l|}{$24.0-27.9 \mathrm{~kg} / \mathrm{m}^{2}$} \\
\hline Excellent & $1,695 / 220,318$ & 1.00 & 1.00 & \\
\hline Good & $2,449 / 341,926$ & $1.07(1.01-1.14)$ & $1.05(0.99-1.12)$ & \\
\hline Fair & $4,688 / 470,278$ & $1.25(1.18-1.33)$ & $1.18(1.11-1.25)$ & \\
\hline Poor & $1,138 / 91,324$ & $1.61(1.49-1.74)$ & $1.42(1.31-1.54)$ & \\
\hline \multicolumn{5}{|l|}{$\geq 28.0 \mathrm{~kg} / \mathrm{m}^{2}$} \\
\hline Excellent & $630 / 63,850$ & 1.00 & 1.00 & \\
\hline Good & $835 / 100,615$ & $1.00(0.90-1.11)$ & 0.98 (0.88-1.09) & \\
\hline Fair & $1,828 / 148,764$ & $1.23(1.12-1.35)$ & $1.17(1.06-1.28)$ & \\
\hline Poor & $541 / 34,291$ & $1.51(1.34-1.71)$ & $1.35(1.20-1.53)$ & \\
\hline History of diabetes & & & & 0.09 \\
\hline \multicolumn{5}{|l|}{ No } \\
\hline Excellent & $3,793 / 604,066$ & 1.00 & 1.00 & \\
\hline Good & $5,894 / 974,658$ & $1.06(1.02-1.11)$ & $1.05(1.00-1.09)$ & \\
\hline Fair & $11,585 / 1,393,500$ & $1.24(1.19-1.29)$ & $1.20(1.15-1.25)$ & \\
\hline Poor & $2,941 / 282,054$ & $1.62(1.54-1.70)$ & $1.53(1.46-1.61)$ & \\
\hline \multicolumn{5}{|l|}{ Yes } \\
\hline Excellent & $411 / 20,823$ & 1.00 & 1.00 & \\
\hline Good & $593 / 36,730$ & $0.98(0.86-1.12)$ & $0.99(0.87-1.12)$ & \\
\hline Fair & $1,747 / 83,374$ & $1.13(1.01-1.26)$ & $1.12(1.00-1.25)$ & \\
\hline Poor & $698 / 29,600$ & $1.32(1.17-1.50)$ & $1.29(1.13-1.46)$ & \\
\hline History of hypertension & & & & 0.33 \\
\hline \multicolumn{5}{|l|}{ No } \\
\hline Excellent & $1,918 / 452,632$ & 1.00 & 1.00 & \\
\hline Good & $2,582 / 696,796$ & $1.04(0.98-1.11)$ & $1.03(0.97-1.10)$ & \\
\hline Fair & $5,069 / 990,674$ & $1.19(1.13-1.26)$ & $1.16(1.10-1.23)$ & \\
\hline Poor & $1,248 / 200,307$ & $1.56(1.45-1.69)$ & $1.49(1.38-1.61)$ & \\
\hline \multicolumn{5}{|l|}{ Yes } \\
\hline Excellent & $2,286 / 172,258$ & 1.00 & 1.00 & \\
\hline Good & $3,905 / 314,592$ & $1.05(1.00-1.11)$ & $1.05(0.99-1.10)$ & \\
\hline
\end{tabular}


Supplementary Table 2. Continued

\begin{tabular}{cccc}
\hline \multirow{2}{*}{ Subgroup } & Cases/person-years & Model $1^{*}$ & ${\text { Model } 2^{+}}^{*}$ Pfor interaction \\
\cline { 3 - 4 } Fair & $8,263 / 486,200$ & $1.23(1.17-1.29)$ & $1.21(1.16-1.27)$ \\
Poor & $2,391 / 111,347$ & $1.57(1.48-1.67)$ & $1.50(1.41-1.59)$ \\
\hline
\end{tabular}

$\mathrm{HR}$, hazard ratio; $\mathrm{Cl}$, confidence interval; $\mathrm{BMI}$, body mass index.

*Model 1: Stratified by age (5 years intervals), sex, region (10 areas) and adjusted for age (continuous), marital status, education, household annual income, occupation, healthcare coverage, housing condition, menopausal status, sleep problems, cigarette smoking, alcohol drinking, physical activity (continuous), body mass index (continuous), and family history of stroke; ${ }^{+}$Model 2: Model 1 plus presence of baseline major depressive episodes, diabetes, hypertension, and other comorbidities (yes, no). The categories and definitions of all categorical variables were illustrated in the 'Covariates' section of the Methods. 
Supplementary Table 3. Stratified analysis: association of age-comparative self-rated health status with risk of first-ever stroke

\begin{tabular}{|c|c|c|c|c|}
\hline \multirow{2}{*}{ Subgroup } & \multirow{2}{*}{ Cases/person-years } & \multicolumn{2}{|c|}{ HR (95\% Cl) } & \multirow{2}{*}{ Pfor interactior } \\
\hline & & Model $1^{*}$ & Model $2^{+}$ & \\
\hline Age & & & & 0.15 \\
\hline \multicolumn{5}{|l|}{$<65$ years old } \\
\hline Better & 2,933/569,076 & 1.00 & 1.00 & \\
\hline Same & 10,792/1,920,839 & $1.22(1.17-1.27)$ & $1.16(1.12-1.21)$ & \\
\hline Worse & $3,426 / 442,010$ & $1.74(1.65-1.83)$ & $1.54(1.46-1.62)$ & \\
\hline \multicolumn{5}{|l|}{$\geq 65$ years old } \\
\hline Better & 1,948/80,198 & 1.00 & 1.00 & \\
\hline Same & $5,843 / 252,335$ & $1.12(1.06-1.18)$ & $1.09(1.03-1.15)$ & \\
\hline Worse & $1,695 / 60,516$ & $1.57(1.46-1.68)$ & $1.48(1.38-1.58)$ & \\
\hline Sex & & & & 0.33 \\
\hline \multicolumn{5}{|l|}{ Men } \\
\hline Better & $2,639 / 295,957$ & 1.00 & 1.00 & \\
\hline Same & $8,006 / 882,687$ & $1.19(1.14-1.25)$ & $1.14(1.09-1.02)$ & \\
\hline Worse & $2,007 / 167,801$ & $1.68(1.58-1.79)$ & $1.53(1.44-1.63)$ & \\
\hline \multicolumn{5}{|l|}{ Women } \\
\hline Better & $2,242 / 353,317$ & 1.00 & 1.00 & \\
\hline Same & $8,629 / 1,290,486$ & $1.17(1.11-1.22)$ & $1.12(1.07-1.18)$ & \\
\hline Worse & $3,114 / 334,724$ & $1.65(1.56-1.75)$ & $1.50(1.41-1.59)$ & \\
\hline Administrative region & & & & 0.49 \\
\hline \multicolumn{5}{|l|}{ Rural } \\
\hline Better & 1,966/300,191 & 1.00 & 1.00 & \\
\hline Same & $9,339 / 1,344,745$ & $1.16(1.10-1.22)$ & $1.13(1.08-1.19)$ & \\
\hline Worse & 2,927/297,984 & $1.64(1.54-1.74)$ & $1.52(1.43-1.61)$ & \\
\hline \multicolumn{5}{|l|}{ Urban } \\
\hline Better & $2,915 / 349,083$ & 1.00 & 1.00 & \\
\hline Same & $7,296 / 828,428$ & $1.19(1.14-1.24)$ & $1.14(1.09-1.19)$ & \\
\hline Worse & $2,194 / 204,542$ & $1.67(1.57-1.77)$ & $1.50(1.41-1.59)$ & \\
\hline Education & & & & $<0.0001$ \\
\hline \multicolumn{5}{|l|}{ No formal school } \\
\hline Better & $845 / 93,743$ & 1.00 & 1.00 & \\
\hline Same & $3,770 / 407,763$ & $1.15(1.06-1.24)$ & $1.12(1.04-1.21)$ & \\
\hline Worse & $1563 / 120,826$ & $1.59(1.45-1.73)$ & $1.47(1.35-1.61)$ & \\
\hline \multicolumn{5}{|l|}{ 1-6 Years } \\
\hline Better & $1,377 / 171,633$ & 1.00 & 1.00 & \\
\hline Same & $6,190 / 729,336$ & $1.18(1.11-1.25)$ & $1.14(1.07-1.21)$ & \\
\hline Worse & $1,685 / 162,048$ & $1.66(1.54-1.79)$ & $1.52(1.41-1.64)$ & \\
\hline \multicolumn{5}{|l|}{ 7-13 Years } \\
\hline Better & $2,123 / 325,179$ & 1.00 & 1.00 & \\
\hline Same & $5,793 / 928,181$ & $1.18(1.13-1.25)$ & $1.13(1.08-1.19)$ & \\
\hline Worse & 1,658/199,293 & $1.67(1.56-1.79)$ & $1.50(1.40-1.60)$ & \\
\hline \multicolumn{5}{|l|}{$\geq 14$ Years } \\
\hline Better & $536 / 58,719$ & 1.00 & 1.00 & \\
\hline Same & $882 / 107,892$ & $1.20(1.07-1.34)$ & $1.16(1.04-1.29)$ & \\
\hline Worse & $215 / 20,359$ & $2.07(1.76-2.45)$ & $1.85(1.56-2.19)$ & \\
\hline
\end{tabular}


Supplementary Table 3. Continued

\begin{tabular}{|c|c|c|c|c|}
\hline \multirow{2}{*}{ Subgroup } & \multirow{2}{*}{ Cases/person-years } & \multicolumn{2}{|c|}{$\mathrm{HR}(95 \% \mathrm{Cl})$} & \multirow{2}{*}{$P$ for interactior } \\
\hline & & Model $1^{*}$ & Model $2^{+}$ & \\
\hline Annual household income & & & & $<0.0001$ \\
\hline \multicolumn{5}{|l|}{$<10,000$ Yuan } \\
\hline Better & $1,466 / 179,416$ & 1.00 & 1.00 & \\
\hline Same & $5,045 / 579,784$ & $1.14(1.07-1.21)$ & $1.12(1.05-1.18)$ & \\
\hline Worse & $2,182 / 203,974$ & $1.58(1.47-1.69)$ & $1.47(1.37-1.58)$ & \\
\hline \multicolumn{5}{|l|}{ 10,000-19,999 Yuan } \\
\hline Better & $1,561 / 186,844$ & 1.00 & 1.00 & \\
\hline Same & $5,470 / 639,557$ & $1.18(1.11-1.25)$ & $1.13(1.06-1.2)$ & \\
\hline Worse & $1,547 / 140,039$ & $1.64(1.52-1.76)$ & $1.48(1.37-1.59)$ & \\
\hline \multicolumn{5}{|l|}{$20,000-34,999$ Yuan } \\
\hline Better & $1,051 / 155,223$ & 1.00 & 1.00 & \\
\hline Same & $3,773 / 566,785$ & $1.20(1.12-1.29)$ & $1.14(1.06-1.22)$ & \\
\hline Worse & $916 / 9,6324$ & $1.82(1.66-2.00)$ & $1.62(1.48-1.78)$ & \\
\hline \multicolumn{5}{|l|}{$\geq 35,000$ Yuan } \\
\hline Better & $803 / 127,792$ & 1.00 & 1.00 & \\
\hline Same & $2,347 / 387,047$ & $1.21(1.11-1.32)$ & $1.16(1.07-1.27)$ & \\
\hline Worse & $476 / 62,189$ & $1.70(1.51-1.91)$ & $1.52(1.34-1.71)$ & \\
\hline Cigarette smoking & & & & 0.001 \\
\hline \multicolumn{5}{|l|}{ Never } \\
\hline Better & $2,439 / 374,729$ & 1.00 & 1.00 & \\
\hline Same & $9,380 / 1,364,521$ & $1.19(1.14-1.25)$ & $1.15(1.10-1.20)$ & \\
\hline Worse & $3,106 / 332,251$ & $1.70(1.61-1.80)$ & $1.54(1.46-1.63)$ & \\
\hline \multicolumn{5}{|l|}{ Former } \\
\hline Better & $498 / 37,911$ & 1.00 & 1.00 & \\
\hline Same & $1,416 / 110,842$ & $1.17(1.06-1.31)$ & $1.14(1.02-1.27)$ & \\
\hline Worse & $476 / 28,582$ & $1.71(1.50-1.96)$ & $1.59(1.38-1.82)$ & \\
\hline \multicolumn{5}{|l|}{ Occasionally } \\
\hline Better & $342 / 41,685$ & 1.00 & 1.00 & \\
\hline Same & $950 / 120,277$ & $1.13(0.99-1.29)$ & $1.09(0.96-1.24)$ & \\
\hline Worse & $267 / 27,851$ & 1.59 (1.34-1.88) & $1.50(1.26-1.78)$ & \\
\hline \multicolumn{5}{|l|}{ Current } \\
\hline Better & $1,602 / 194,949$ & 1.00 & 1.00 & \\
\hline Same & $4,889 / 577,533$ & $1.17(1.10-1.24)$ & $1.12(1.05-1.19)$ & \\
\hline Worse & $1,272 / 113,842$ & 1.59 (1.47-1.72) & $1.44(1.33-1.56)$ & \\
\hline Alcohol drinking & & & & $<0.001$ \\
\hline \multicolumn{5}{|l|}{ Never } \\
\hline Better & 1,530/227,108 & 1.00 & 1.00 & \\
\hline Same & $7,618 / 1,028,927$ & $1.24(1.17-1.32)$ & $1.20(1.13-1.27)$ & \\
\hline Worse & $2,716 / 254,234$ & 1.78 (1.66-1.90) & $1.62(1.51-1.73)$ & \\
\hline \multicolumn{5}{|l|}{ Former } \\
\hline Better & $84 / 6,686$ & 1.00 & 1.00 & \\
\hline Same & $451 / 29,899$ & $1.19(0.93-1.52)$ & $1.15(0.90-1.46)$ & \\
\hline Worse & $228 / 13,500$ & $1.76(1.35-2.29)$ & $1.66(1.27-2.17)$ & \\
\hline Occasionally & & & & \\
\hline
\end{tabular}


Supplementary Table 3. Continued

\begin{tabular}{|c|c|c|c|c|}
\hline \multirow{2}{*}{ Subgroup } & \multirow{2}{*}{ Cases/person-years } & \multicolumn{2}{|c|}{ HR (95\% Cl) } & \multirow{2}{*}{$P$ for interactior } \\
\hline & & Model $1^{*}$ & Model $2^{+}$ & \\
\hline Better & $1,971 / 266,866$ & 1.00 & 1.00 & \\
\hline Same & $5,546 / 753,542$ & $1.15(1.10-1.22)$ & $1.11(1.06-1.18)$ & \\
\hline Worse & 1,489/167,770 & $1.59(1.48-1.71)$ & $1.44(1.34-1.55)$ & \\
\hline \multicolumn{5}{|l|}{ Weekly } \\
\hline Better & $1,296 / 148,614$ & 1.00 & 1.00 & \\
\hline Same & $3,020 / 360,804$ & $1.12(1.05-1.20)$ & $1.07(1.00-1.15)$ & \\
\hline Worse & $699 / 67,021$ & $1.56(1.42-1.72)$ & $1.42(1.29-1.56)$ & \\
\hline Physical activity & & & & 0.88 \\
\hline \multicolumn{5}{|l|}{ Low } \\
\hline Better & $2,463 / 182,125$ & 1.00 & 1.00 & \\
\hline Same & $8,747 / 654,218$ & $1.20(1.14-1.25)$ & $1.15(1.10-1.20)$ & \\
\hline Worse & 2,855/170,798 & 1.69 (1.59-1.78) & $1.54(1.45-1.63)$ & \\
\hline \multicolumn{5}{|l|}{ Moderate } \\
\hline Better & $1,538 / 240,492$ & 1.00 & 1.00 & \\
\hline Same & $4,763 / 722,904$ & $1.15(1.08-1.22)$ & $1.11(1.05-1.18)$ & \\
\hline Worse & $1,412 / 168,729$ & $1.63(1.51-1.76)$ & $1.47(1.36-1.59)$ & \\
\hline \multicolumn{5}{|l|}{ High } \\
\hline Better & $880 / 226,657$ & 1.00 & 1.00 & \\
\hline Same & $3,125 / 796,052$ & $1.17(1.08-1.26)$ & $1.14(1.05-1.23)$ & \\
\hline Worse & $854 / 162,998$ & $1.62(1.47-1.79)$ & $1.49(1.35-1.65)$ & \\
\hline $\mathrm{BMI}$ & & & & 0.22 \\
\hline \multicolumn{5}{|l|}{$<18.5 \mathrm{~kg} / \mathrm{m}^{2}$} \\
\hline Better & $127 / 15,751$ & 1.00 & 1.00 & \\
\hline Same & $696 / 90,223$ & $1.06(0.87-1.30)$ & $1.07(0.88-1.31)$ & \\
\hline Worse & $345 / 33,726$ & $1.45(1.17-1.80)$ & $1.44(1.16-1.80)$ & \\
\hline \multicolumn{5}{|l|}{$18.5-23.9 \mathrm{~kg} / \mathrm{m}^{2}$} \\
\hline Better & $1,998 / 319,646$ & 1.00 & 1.00 & \\
\hline Same & $7,818 / 1,168,853$ & $1.21(1.15-1.27)$ & $1.17(1.11-1.23)$ & \\
\hline Worse & $2,325 / 266,943$ & $1.71(1.60-1.82)$ & $1.56(1.46-1.66)$ & \\
\hline \multicolumn{5}{|l|}{$24.0-27.9 \mathrm{~kg} / \mathrm{m}^{2}$} \\
\hline Better & $1,986 / 240,072$ & 1.00 & 1.00 & \\
\hline Same & $5,937 / 705,406$ & $1.18(1.12-1.25)$ & $1.13(1.08-1.20)$ & \\
\hline Worse & $1,667 / 146,475$ & $1.71(1.60-1.83)$ & $1.53(1.42-1.64)$ & \\
\hline \multicolumn{5}{|l|}{$\geq 28.0 \mathrm{~kg} / \mathrm{m}^{2}$} \\
\hline Better & $770 / 73,806$ & 1.00 & 1.00 & \\
\hline Same & $2,184 / 208,681$ & $1.11(1.02-1.21)$ & $1.07(0.98-1.17)$ & \\
\hline Worse & $784 / 55,382$ & $1.57(1.41-1.74)$ & $1.42(1.28-1.58)$ & \\
\hline History of diabetes & & & & 0.43 \\
\hline \multicolumn{5}{|l|}{ No } \\
\hline Better & $4,431 / 626,593$ & 1.00 & 1.00 & \\
\hline Same & $14,764 / 2,075,542$ & $1.17(1.13-1.21)$ & $1.14(1.10-1.18)$ & \\
\hline Worse & $4,137 / 458,445$ & $1.61(1.54-1.68)$ & $1.53(1.47-1.60)$ & \\
\hline \multicolumn{5}{|l|}{ Yes } \\
\hline Better & $450 / 22,681$ & 1.00 & 1.00 & \\
\hline
\end{tabular}


Supplementary Table 3. Continued

\begin{tabular}{lccc}
\hline \multirow{2}{*}{$\begin{array}{l}\text { Subgroup } \\
\text { Same }\end{array}$} & Cases/person-years & Model $1^{*}$ & Model $2^{+}$ \\
\cline { 3 - 3 } Worse & $1,871 / 97,632$ & $1.12(1.01-1.25)$ & $1.11(1.00-1.23)$ \\
History of hypertension & $984 / 44,081$ & $1.43(1.28-1.61)$ & $1.40(1.25-1.58)$ \\
No & & & 0.07 \\
Better & & & 1.00 \\
Same & $2,130 / 462,339$ & 1.00 & $1.14(1.09-1.20)$ \\
Worse & $6,460 / 1,481,015$ & $1.16(1.10-1.22)$ & $1.50(1.41-1.61)$ \\
Yes & $1778 / 330,834$ & $1.58(1.48-1.68)$ & 1.00 \\
Better & & & $1.13(1.09-1.18)$ \\
Same & $2,751 / 186,935$ & 1.00 & $1.52(1.44-1.61)$ \\
Worse & $10,175 / 692,158$ & $1.15(1.10-1.20)$ & \\
\hline
\end{tabular}

$\mathrm{HR}$, hazard ratio; $\mathrm{Cl}$, confidence interval; $\mathrm{BMI}$, body mass index.

*Model 1: Stratified by age (5 years intervals), sex, region (10 areas) and adjusted for age (continuous), marital status, education, household annual income, occupation, healthcare coverage, housing condition, menopausal status, sleep problems, cigarette smoking, alcohol drinking, physical activity (continuous), body mass index (continuous), and family history of stroke; ${ }^{+}$Model 2: Model 1 plus presence of baseline major depressive episodes, diabetes, hypertension, and other comorbidities (yes, no). The categories and definitions of all categorical variables were illustrated in the 'Covariates' section of the Methods. 
Supplementary Table 4. Sensitivity analysis: association of self-rated health status measures with risk of first-ever stroke*

\begin{tabular}{|c|c|c|c|c|}
\hline \multirow[b]{2}{*}{ Outcome categories } & \multirow[b]{2}{*}{ Exposure categories } & \multicolumn{3}{|c|}{$\mathrm{HR}(95 \% \mathrm{Cl})$} \\
\hline & & No major depression episodes ${ }^{\dagger}$ & No comorbidities $^{\dagger}$ & $\begin{array}{c}\text { Not died or developed stroke ir } \\
\text { the first } 2 \text { years }\end{array}$ \\
\hline \multirow[t]{9}{*}{ First-ever stroke } & General SRH & & & \\
\hline & Excellent & 1.00 & 1.00 & 1.00 \\
\hline & Good & $1.04(1.00-1.08)$ & $1.07(1.00-1.16)$ & $1.03(0.99-1.08)$ \\
\hline & Fair & $1.19(1.15-1.23)$ & $1.20(1.12-1.28)$ & $1.18(1.13-1.23)$ \\
\hline & Poor & $1.49(1.42-1.56)$ & $1.55(1.40-1.71)$ & $1.43(1.36-1.51)$ \\
\hline & Age-comparative SRH & & & \\
\hline & Better & 1.00 & 1.00 & 1.00 \\
\hline & Same & $1.13(1.09-1.17)$ & $1.18(1.11-1.26)$ & $1.11(1.07-1.16)$ \\
\hline & Worse & $1.51(1.45-1.58)$ & $1.54(1.41-1.68)$ & $1.44(1.38-1.51)$ \\
\hline \multirow[t]{9}{*}{ Hemorrhagic stroke } & General SRH & & & \\
\hline & Excellent & 1.00 & 1.00 & 1.00 \\
\hline & Good & $1.09(0.99-1.20)$ & $1.01(0.84-1.23)$ & $1.06(0.95-1.18)$ \\
\hline & Fair & $1.18(1.08-1.29)$ & $1.11(0.93-1.33)$ & $1.16(1.05-1.28)$ \\
\hline & Poor & $1.62(1.45-1.80)$ & $1.47(1.15-1.89)$ & $1.52(1.34-1.72)$ \\
\hline & Age-comparative SRH & & & \\
\hline & Better & 1.00 & 1.00 & 1.00 \\
\hline & Same & $1.14(1.05-1.24)$ & $1.26(1.06-1.50)$ & $1.14(1.04-1.25)$ \\
\hline & Worse & $1.57(1.43-1.73)$ & $1.68(1.34-2.10)$ & $1.49(1.34-1.66)$ \\
\hline \multirow[t]{9}{*}{ Ischemic stroke } & General SRH & & & \\
\hline & Excellent & 1.00 & 1.00 & 1.00 \\
\hline & Good & 1.03 (0.99-1.08) & $1.08(0.99-1.16)$ & $1.03(0.98-1.08)$ \\
\hline & Fair & $1.20(1.15-1.24)$ & $1.22(1.13-1.31)$ & $1.18(1.13-1.24)$ \\
\hline & Poor & $1.45(1.38-1.53)$ & $1.51(1.36-1.69)$ & $1.40(1.32-1.49)$ \\
\hline & Age-comparative SRH & & & \\
\hline & Better & 1.00 & 1.00 & 1.00 \\
\hline & Same & $1.14(1.10-1.18)$ & $1.17(1.09-1.25)$ & $1.12(1.08-1.16)$ \\
\hline & Worse & $1.49(1.43-1.57)$ & $1.48(1.34-1.63)$ & $1.43(1.36-1.51)$ \\
\hline \multirow[t]{9}{*}{ Fatal stroke } & General SRH & & & \\
\hline & Excellent & 1.00 & 1.00 & 1.00 \\
\hline & Good & $1.06(0.94-1.20)$ & $1.16(0.91-1.48)$ & $1.05(0.92-1.20)$ \\
\hline & Fair & $1.27(1.14-1.42)$ & $1.23(0.98-1.55)$ & $1.28(1.13-1.46)$ \\
\hline & Poor & $1.91(1.68-2.18)$ & 2.16 (1.62-2.88) & $1.86(1.60-2.15)$ \\
\hline & Age-comparative SRH & & & \\
\hline & Better & 1.00 & 1.00 & 1.00 \\
\hline & Same & $1.17(1.06-1.29)$ & $1.28(1.04-1.58)$ & $1.16(1.04-1.29)$ \\
\hline & Worse & $1.81(1.61-2.03)$ & $1.97(1.52-2.55)$ & $1.70(1.50-1.94)$ \\
\hline
\end{tabular}


Supplementary Table 4. Continued

\begin{tabular}{|c|c|c|c|c|}
\hline \multirow[b]{2}{*}{ Outcome categories } & \multirow[b]{2}{*}{ Exposure categories } & \multicolumn{3}{|c|}{$\mathrm{HR}(95 \% \mathrm{Cl})$} \\
\hline & & No major depression episodes ${ }^{\dagger}$ & No comorbidities ${ }^{\dagger}$ & $\begin{array}{c}\text { Not died or developed stroke in } \\
\text { the first } 2 \text { years }{ }^{\S}\end{array}$ \\
\hline \multirow[t]{9}{*}{ Non-fatal stroke } & General SRH & & & \\
\hline & Excellent & 1.00 & 1.00 & 1.00 \\
\hline & Good & $1.04(1.00-1.08)$ & $1.06(0.98-1.14)$ & $1.03(0.98-1.08)$ \\
\hline & Fair & $1.18(1.14-1.23)$ & $1.20(1.12-1.29)$ & $1.17(1.12-1.22)$ \\
\hline & Poor & $1.43(1.36-1.51)$ & $1.48(1.33-1.65)$ & $1.38(1.30-1.46)$ \\
\hline & Age-comparative SRH & & & \\
\hline & Better & 1.00 & 1.00 & 1.00 \\
\hline & Same & $1.13(1.09-1.17)$ & $1.17(1.10-1.25)$ & $1.11(1.07-1.15)$ \\
\hline & Worse & $1.47(1.40-1.54)$ & $1.49(1.35-1.63)$ & $1.41(1.34-1.48)$ \\
\hline
\end{tabular}

$\mathrm{HR}$, hazard ratio; $\mathrm{Cl}$, confidence interval; $\mathrm{SRH}$, self-rated health status.

*HR $(95 \% \mathrm{Cl})$ were calculated after stratification by age (5 years intervals), sex, region (10 areas) and adjustment for age (continuous), marital status, education, annual household income, occupation, healthcare coverage, housing condition, menopausal status, sleep problems, cigarette smoking, alcohol drinking, physical activity (continuous), body mass index (continuous), family history of stroke, presence of baseline major depressive episodes, diabetes, hypertension and other prevalent diseases (yes, no). The categories and definitions of all categorical variables were illustrated in the 'Covariates' section of the Methods; ${ }^{+}$2,972 participants with baseline major depression episodes were excluded and 483,569 remained for analysis; ${ }^{\ddagger} 238,007$ participants with baseline comorbidities were excluded and 248,534 remained for analysis; ${ }^{\S} 8,216$ participants who died or developed stroke in the first 2 years of follow-up were excluded and 478,325 remained for analysis. 
Supplementary Table 5. Incorporating two measures in one model: association of SRH status measures with risk of first-ever stroke

\begin{tabular}{|c|c|c|c|c|}
\hline \multirow{2}{*}{ Outcome categories } & \multirow{2}{*}{ Exposures } & \multicolumn{3}{|c|}{$\mathrm{HR}(95 \% \mathrm{Cl})$} \\
\hline & & $A^{*}$ & $\mathrm{~B}^{+}$ & $\mathrm{C}^{\ddagger}$ \\
\hline \multirow[t]{7}{*}{ Total stroke } & General SRH (reference=excellent) & & & \\
\hline & Good & $1.04(1.00-1.08)$ & & $1.01(0.97-1.06)$ \\
\hline & Fair & $1.19(1.15-1.23)$ & & $1.11(1.06-1.15)$ \\
\hline & Poor & $1.49(1.42-1.56)$ & & $1.21(1.14-1.29)$ \\
\hline & Age-comparative SRH (reference=better) & & & \\
\hline & Same & & $1.13(1.10-1.17)$ & $1.09(1.05-1.13)$ \\
\hline & Worse & & $1.52(1.46-1.58)$ & $1.34(1.27-1.42)$ \\
\hline \multirow[t]{7}{*}{ Hemorrhagic stroke } & General SRH (reference=excellent) & & & \\
\hline & Good & $1.09(0.99-1.20)$ & & $1.06(0.95-1.17)$ \\
\hline & Fair & $1.18(1.08-1.29)$ & & $1.09(0.98-1.20)$ \\
\hline & Poor & $1.62(1.46-1.81)$ & & $1.30(1.14-1.50)$ \\
\hline & Age-comparative SRH (reference=better) & & & \\
\hline & Same & & $1.14(1.05-1.23)$ & $1.10(1.00-1.20)$ \\
\hline & Worse & & $1.57(1.43-1.73)$ & $1.35(1.20-1.53)$ \\
\hline \multirow[t]{7}{*}{ Ischemic stroke } & General SRH (reference=excellent) & & & \\
\hline & Good & $1.03(0.99-1.08)$ & & $1.01(0.96-1.05)$ \\
\hline & Fair & $1.20(1.15-1.25)$ & & $1.12(1.07-1.17)$ \\
\hline & Poor & $1.45(1.38-1.53)$ & & $1.19(1.11-1.27)$ \\
\hline & Age-comparative SRH (reference=better) & & & \\
\hline & Same & & $1.14(1.10-1.18)$ & $1.09(1.05-1.13)$ \\
\hline & Worse & & $1.50(1.43-1.57)$ & $1.34(1.26-1.42)$ \\
\hline \multirow[t]{7}{*}{ Fatal stroke } & General SRH (reference=excellent) & & & \\
\hline & Good & $1.06(0.94-1.20)$ & & $1.02(0.90-1.16)$ \\
\hline & Fair & $1.27(1.13-1.42)$ & & $1.15(1.01-1.31)$ \\
\hline & Poor & $1.92(1.69-2.19)$ & & $1.47(1.25-1.74)$ \\
\hline & Age-comparative SRH (reference=better) & & & \\
\hline & Same & & $1.17(1.06-1.29)$ & $1.10(0.98-1.23)$ \\
\hline & Worse & & $1.82(1.63-2.04)$ & $1.43(1.23-1.66)$ \\
\hline \multirow[t]{7}{*}{ Non-fatal stroke } & General SRH (reference=excellent) & & & \\
\hline & Good & $1.04(1.00-1.08)$ & & $1.01(0.97-1.06)$ \\
\hline & Fair & $1.18(1.14-1.23)$ & & $1.11(1.06-1.15)$ \\
\hline & Poor & $1.43(1.36-1.51)$ & & $1.18(1.10-1.25)$ \\
\hline & Age-comparative SRH (reference=better) & & & \\
\hline & Same & & $1.13(1.09-1.17)$ & $1.08(1.04-1.13)$ \\
\hline & Worse & & $1.47(1.41-1.54)$ & $1.33(1.25-1.40)$ \\
\hline
\end{tabular}

$\mathrm{SRH}$, self-rated health; $\mathrm{HR}$, hazard ratio; $\mathrm{Cl}$, confidence interval.

*Only general SRH was included in Model 2 (stratified by age [5 years intervals], sex, region [10 areas] and adjusted for age [continuous], marital status, education, annual household income, occupation, healthcare coverage, housing condition, menopausal status, sleep problems, cigarette smoking, alcohol drinking, physical activity [continuous], body mass index [continuous], family history of stroke, presence of baseline major depressive episodes, diabetes, hypertension, and other prevalent diseases [yes, no]). The categories and definitions of all categorical variables were illustrated in the 'Covariates' section of the Methods; ${ }^{+}$Only age-comparative SRH was included in Model 2; ${ }^{*}$ Both general SRH and age-comparative SRH were included in Model 2. 

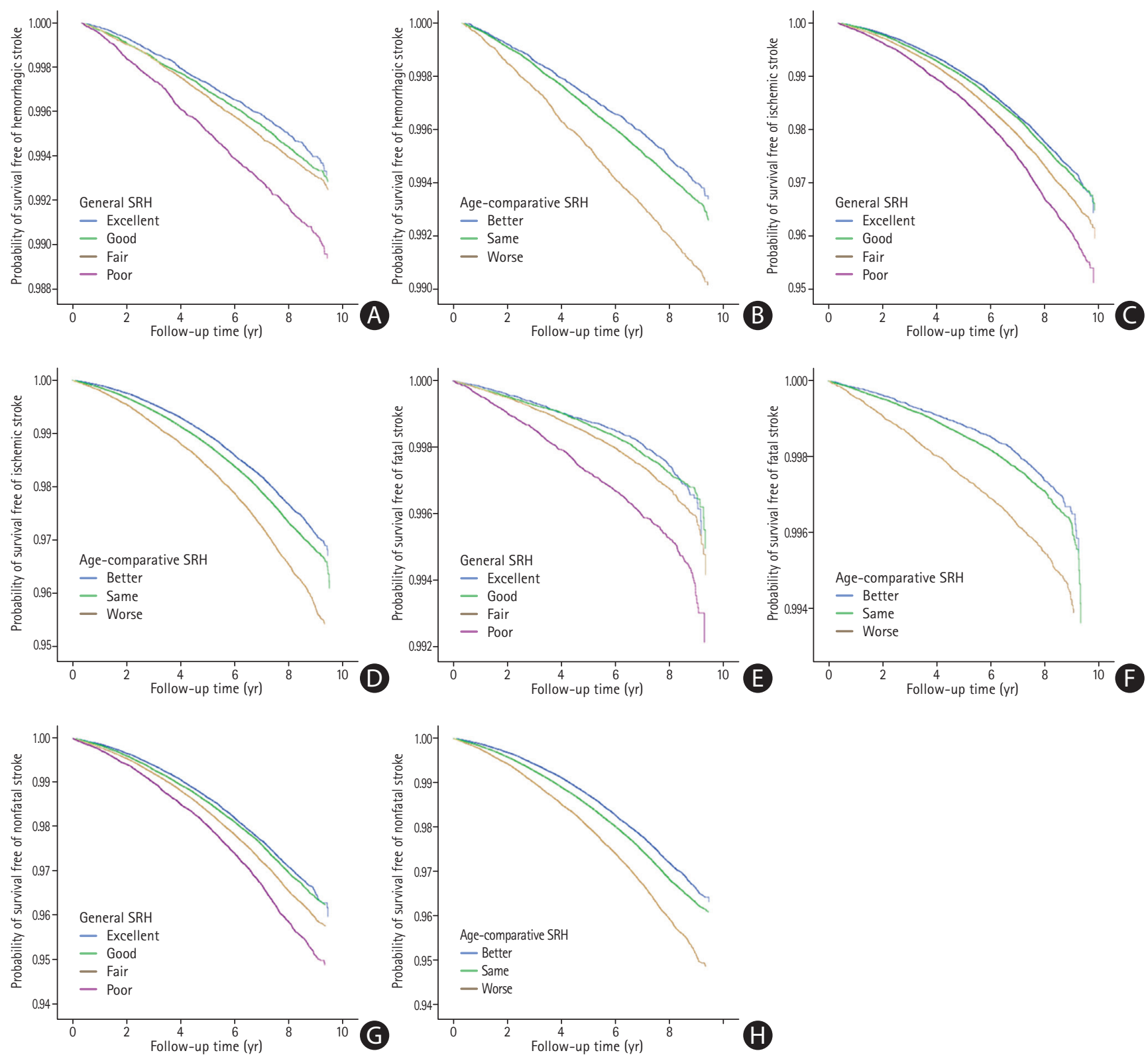

Supplemental Figure 1. Survival curves for participants according to self-rated health (SRH) categories. (A) Survival curves free of hemorrhagic stroke stratified by general SRH. (B) Survival curves free of hemorrhagic stroke stratified by age-comparative SRH. (C) Survival curves free of ischemic stroke stratified by general SRH. (D) Survival curves free of ischemic stroke stratified by age-comparative SRH. (E) Survival curves free of fatal stroke stratified by general SRH. (F) Survival curves free of fatal stroke stratified by age-comparative SRH. (G) Survival curves free of non-fatal stroke stratified by general SRH. (H) Survival curves free of non-fatal stroke stratified by age-comparative SRH. All survival curves were stratified by age (5 years intervals), sex, region (10 areas) and adjusted for age (continuous), marital status, education, annual household income, occupation, healthcare coverage, housing condition, menopausal status, sleep problems, cigarette smoking, alcohol drinking, physical activity (continuous), body mass index (continuous), family history of stroke, presence of baseline major depressive episodes, diabetes, hypertension, and other prevalent diseases (yes, no). The categories and definitions of all categorical variables were illustrated in the 'Covariates' section of the Methods. 